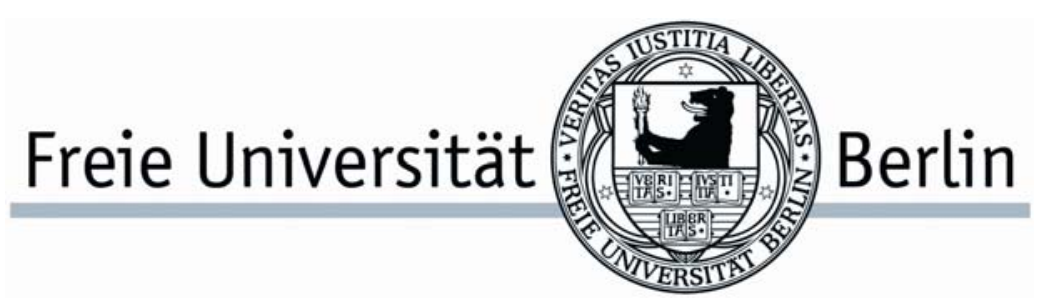

Diskussionsbeiträge des Fachbereichs Wirtschaftswissenschaft der Freien Universität Berlin

Volkswirtschaftliche Reihe

2008/14

\title{
The ECB's Monetary Analysis Revisited
}

Helge Berger ; Thomas Harjes ; Emil Stavrev 


\title{
The ECB’s Monetary Analysis Revisited
}

\author{
Prepared by Helge Berger, Thomas Harjes, and Emil Stavrev*
}

July 2008

\begin{abstract}
$\underline{\text { Abstract }}$
Monetary aggregates continue to play an important role in the ECB's policy strategy. This paper revisits the case for money, surveying the ongoing theoretical and empirical debate. The key conclusion is that an exclusive focus on non-monetary factors alone may leave the ECB with an incomplete picture of the economy. However, treating monetary factors as a separate matter is a second-best solution. Instead, a general-equilibrium inspired analytical framework that merges the economic and monetary "pillars" of the ECB's policy strategy appears the most promising way forward. The role played by monetary aggregates in such unified framework may be rather limited. However, an integrated framework would facilitate the presentation of policy decisions by providing a clearer narrative of the relative role of money in the interaction with other economic and financial sector variables, including asset prices, and their impact on consumer prices.
\end{abstract}

JEL Classification Numbers: C11, C30, E31, E40

Keywords: ECB, monetary analysis, monetary pillar, New Keynesian model, DSGE model, P* model, Twopillar Phillips curve, VAR model, generalized dynamic factor model

*Author’s E-Mail Address: helge.berger@fu-berlin.de; tharjes@imf.org; estavrev@imf.org. 


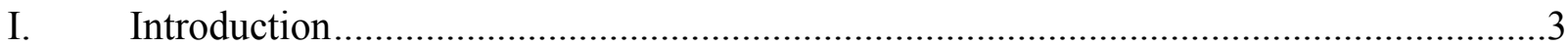

II. A Brief Guide Monetary Analysis in the ECB's Strategy and its

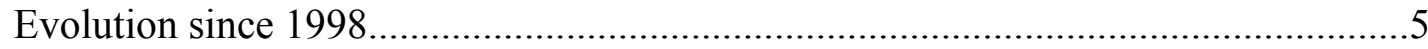

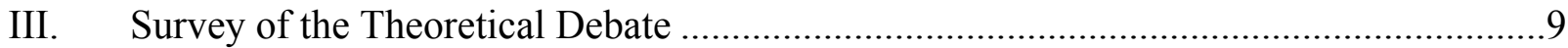

A. The Cashless Benchmark: the Standard New Keynesian

General Equilibrium Model ..................................................................10

B. The Case for Money in the Generalized New Keynesian Model .................12

C. The Case for Money in Partial Equilibrium Models.....................................22

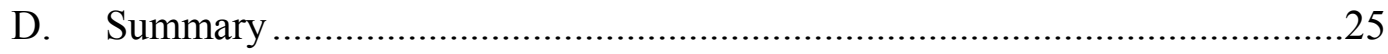

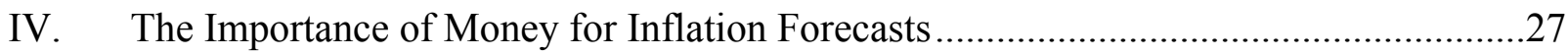

A. A Brief Survey of the Empirical Literature ……….....................................27

B. A Systematic Analysis of the Information Content of Money ......................29

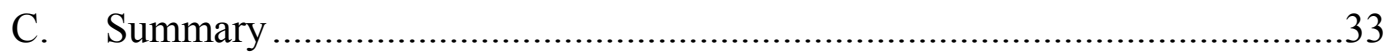

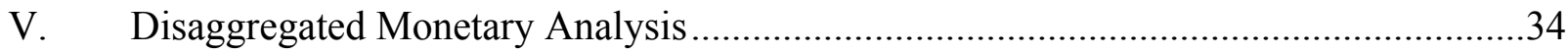

A. The Background of the ECB's Disaggregate Monetary Analysis .................35

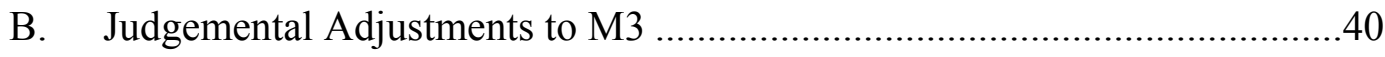

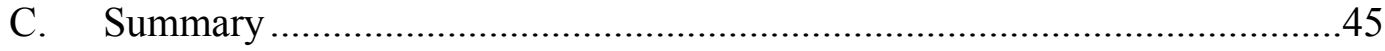

VI. How Time Path Dependent should the ECB's Monetary Strategy Be?..........................46

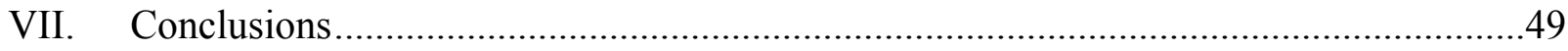

Boxes

1. Securitization and the Bank Lending Channel............................................................44

Figures

1. M3 Growth and Policy Rate in the Euro Area, 1999-2008 ………....................................3

2. A Stylized View of the Role of Money in the ECB's Monetary Strategy ............................6

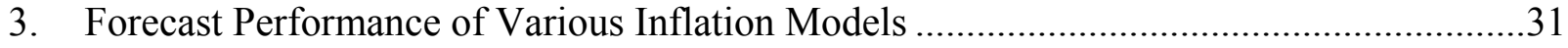

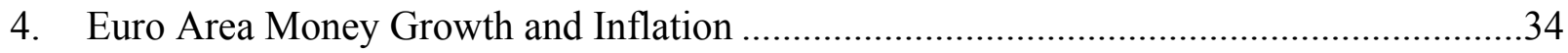

5. Income Velocity in the Euro Area and Other G-7 Countries ...............................................36

6. Annual Board Money Growth in the U.S. and in the Euro Area .......................................41

7. Annual M3 Growth, and M3 Velocity (in logs) and Its Trend,

With and Without Portfolio Adjustment ...................................................................42

8. Decomposition of Net-Assets of German Banks vis-à-vis Non-Residents ..........................45

Tables

1. Arguments in Favor of a More Prominent Role for Money: Overview ………………........27

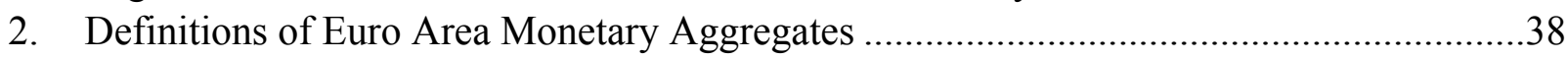

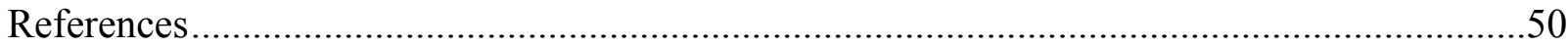




\section{INTRODUCTION}

Money plays an important role in the European Central Bank's (ECB's) monetary policy strategy. According to the ECB, monetary analysis (formerly known as the "monetary pillar") helps to guide the policy-making process of the Governing Council by providing information on "medium to long-term trends in inflation, given the close relationship between money and prices over extended horizons" (ECB, 2003, p. 79). It also serves as a communication device by stressing the ECB commitment to price stability. While a certain proximity to the monetary targeting framework of the German Bundesbank was intentional when the ECB announced its strategy, the ECB later made it clear that monetary analysis is neither its sole nor its most important guide to policy decisions. Today, the prime function of monetary analysis is to serve "as a means of cross-checking, from a medium to long-term perspective, the short to medium-term indications coming from economic analysis" (ECB 2003, p. 87), which is a broad-based analysis of price developments in the short to medium run based on non-monetary indicators. Still, the continued explicit reliance on money to guide monetary policy is a distinguishing feature of the ECB's framework compared to that of other central banks.

Figure 1. M3 Growth and Policy Rate in the Euro Area, 1999-2008

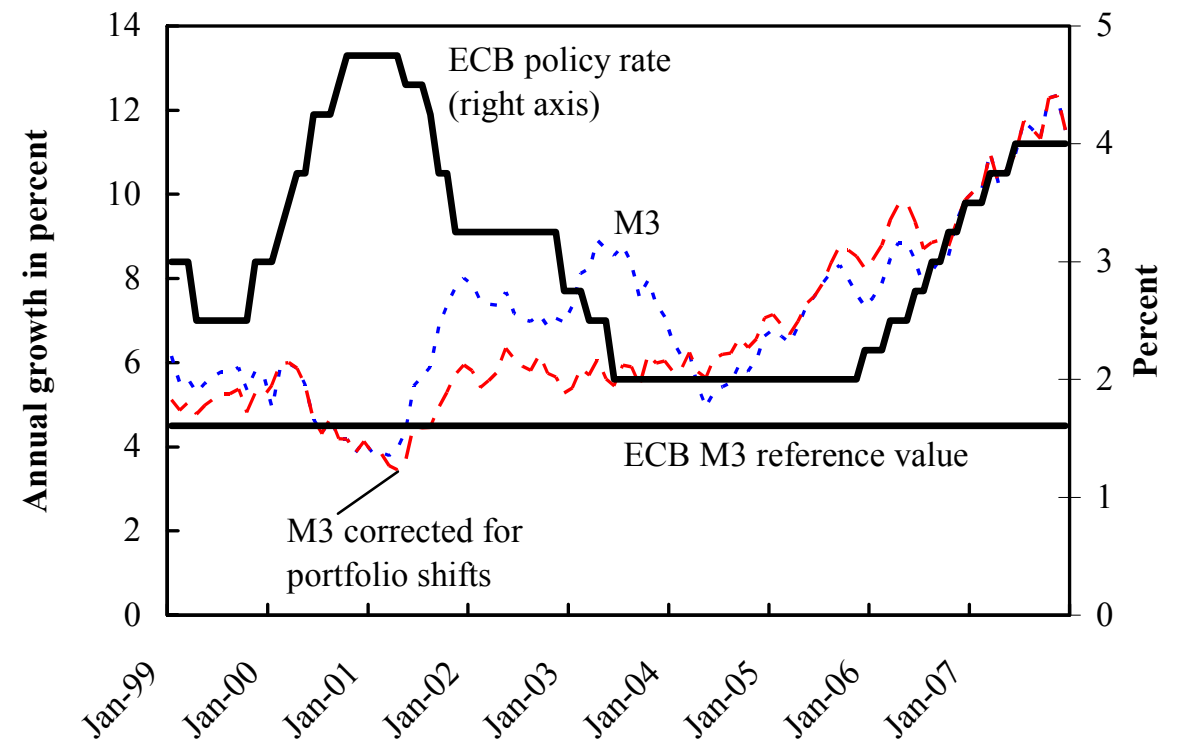

Source: ECB.

In practice, the implementation of the money-based element of the ECB's policy strategy has been challenging. In particular, the repeated surges of nominal M3 growth beyond the ECB's reference value (see Figure 1) have made it increasingly difficult for outside observers to understand the transmission of monetary analysis into policy action, however indirect and conditional. Despite an impressive effort by the ECB to identify and explain to the wider public the various special factors (such as international portfolio shifts) potentially clouding the informational content of the monetary indicator, financial markets appear to no longer put appreciable weight on ECB communication relating to the monetary analysis. Instead, they appear to focus almost exclusively on communication related to economic analysis. 
At the same time, academic economists are debating intensively the ECB's monetary analysis. ECB watchers have criticized what they perceive as a breakdown in communication in the implementation of the "monetary pillar." More fundamentally, recent theoretical research casts doubt on the notion that monetary policy, almost by definition, needs to be based on a theoretical framework giving prominent role to monetary factors. Indeed, the standard New Keynesian dynamic general equilibrium (GE) model focuses almost exclusively on the interest rate channel of monetary policy, reducing the role of money to a unit of account. As a consequence, the underlying theoretical rationale of the "two pillar" approach has been questioned. Empirically, too, the case of a causal or even an informational role of money for inflation has been challenged. And while others disagree with these theoretical and empirical results, it is probably fair to say that there remains much debate about the role of money in monetary policy.

This discussion is highly relevant from the ECB's perspective, and policy makers appear to follow it closely. The ECB's evaluation of the role of money in its monetary strategy in 2003 already reflected some of the arguments discussed above, and the ECB has taken an even more active role in this debate since. For instance, in November 2006 the ECB hosted a conference on "The Role of Money-Money and Monetary Policy in the Twenty-First Century", and the proceedings suggest a lively debate joint by both central bankers and academics. ${ }^{1}$ That the topic is one where both areas often converge is also highlighted by a recent stream of working papers involving euro-area central bank staff members discussing, among other things, the stability of euro-area money demand and the implications for ECB policy. $^{2}$

Against this background, this paper revisits the case for the ECB's "monetary pillar." Starting from a brief description of the evolution of the ECB's monetary pillar (Section II), the paper surveys the ongoing theoretical and empirical debate on the role of money for inflation as well as arguments in support of a prominent role for money in monetary policy in partial as well in general equilibrium settings (Sections III and IV). In addition to the underlying macroeconomics, the paper also reviews the more disaggregate aspect of the ECB's monetary analysis, taking a closer look at the ECB's experience with explaining the shorter-run movements of monetary aggregates in light of financial market integration and innovation (Section V). Finally, some theoretical and institutional arguments for a steady hand in developing the ECB's monetary strategy further are discussed (Section VI). Section VII concludes.

\footnotetext{
${ }^{1}$ See Beyer and Reichlin (2008).

2 This exchange was reflected in a speech by Banque de France Governor Christian Noyer (2007), who suggested excluding from the ECB's money growth figures growth stemming from money holding by private equity or investment funds. ECB Vice-President Lucas Papademos, also in a public appearance, was later reported to refute the idea, however, pointing to the role of the broader aggregate as an inflation indicator (Reuters 2007). Bloomberg (2007) reported around the same time that ECB President Claude Trichet and German Bundesbank Governor Axel Weber in public supported an important role for money in ECB monetary policy (see also Dow Jones 2007).
} 
The first policy conclusion resulting from this analysis is that integrating monetary and economic analysis in a unified monetary strategy framework would have several advantages. There is little doubt that money plays a larger role for inflation, both theoretically and empirically, than some critics let on. But its contribution relative to other (or, in ECB parlance, economic) factors is often limited and, thus, can and should be put into perspective and interpreted in a consistent setup that also allows for feedbacks between the different determinants of inflation. Modern general equilibrium models provide such a tool by allowing for a structural and/or informative role for money in addition to key economic factors, and can help lift the idea of cross checking from the confinements of partial equilibrium approaches. This will further clarify the ECB's monetary strategy and greatly simplify the communication of policy implications.

A second policy recommendation would be to shift the emphasis of disaggregated monetary analysis from judgmental M3 adjustments to providing input into financial stability analysis. Little is to be gained from attempts to adjust the M3 reference value approach to the endless stream of financial innovation in a systematic manner. And any underlying theoretical insight should be discussed in the unified analytical framework. However, there may be valuable information in following the financial sector developments underlying aggregate liquidity from a stability perspective.

Overall, with the ECB's reputation now well established, there is little or no downside risk to refining its monetary strategy within a unified framework. This would facilitate regaining markets' attention for monetary developments as their implications for the economy, notably prices, and finance are increasingly better understood.

\section{A Brief Guide Monetary Analysis In the ECB's Strategy and Its Evolution SINCE 1998}

Money is a key ingredient in the ECB's monetary strategy, which guides its policy-making process and communication with the public (ECB 1999, ECB 2003b-see Figure 2 for an overview). ${ }^{3}$ Guidance for the policy process is provided by an analytical framework, encompassing (using the ECB's post-2003 terminology) monetary and economic analysis to ensure that the Governing Council has the information necessary to align monetary policy with the goal of price stability. The same framework also serves as a vehicle for communication, where it can help to establish confidence that the ECB is credibly committed to and able to achieve this goal. While economic analysis is focused on the short- and medium-run inflation outlook based on a broad range of non-monetary factors, monetary analysis aims at the medium- to long-run implications of monetary developments for inflation. Note that the medium-run time horizon where monetary and economic analysis overlap — probably best defined as between one year and four to five years, including the business cycle frequency - is perhaps to most relevant from a policy perspective. It is well

\footnotetext{
${ }^{3}$ According to the ECB (1999, p. 43), in addition to the guiding goal of price stability, the monetary strategy "imposes a clear structure on the policy-making process" and is a "vehicle for communicating with the public." See also ECB (2004a). In what follows, we focus only on the two latter elements.
} 
known that monetary policy operates with lags and is commonly thought to influence inflation most after 6 to 8 quarters. ${ }^{4}$

Figure 2: A Stylized View of the Role of Money in the ECB's Monetary Strategy

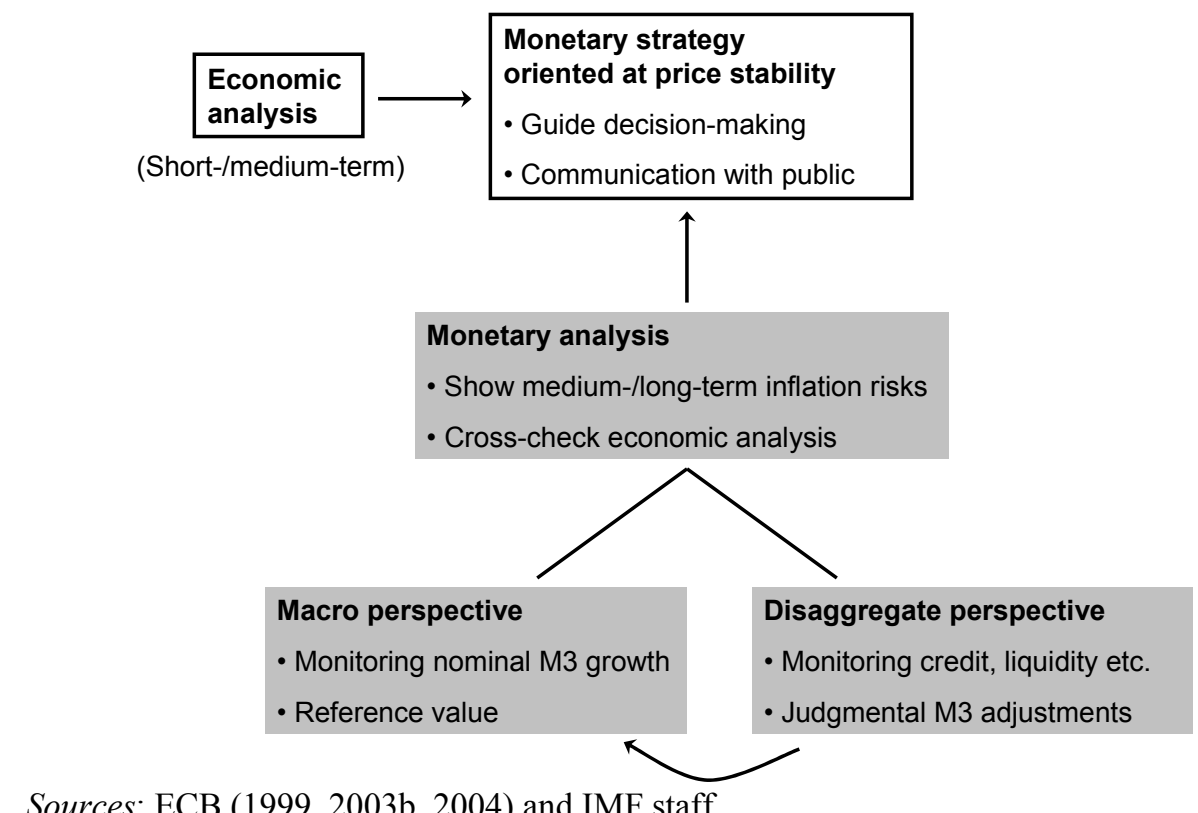

Monetary analysis encompasses what, for the present purposes, can be called a macroeconomic and a disaggregate (or more micro-oriented) perspective. The macroeconomic part of the analysis is implemented predominantly through a comparison of annual nominal M3 growth with a reference value, which is to reflect medium- to long-term monetary developments in line with the ECB's goal of price stability. However, early on the ECB (1998) was careful to state that interest rates would not be adjusted mechanically in response to deviations of actual growth from the reference value, and that it had not bound itself to an intermediate monetary target - as had one of its predecessors, the German Bundesbank. The reference value was to be used to discover and understand inflationary pressure building over the medium run: "in the first instance, a deviation of monetary growth from the reference value will prompt further analysis to identify and interpret the economic disturbance that caused the deviation" (ECB 1999, p.49). And only if this analysis indicated a relevant threat to price stability, the ECB would act. ${ }^{5}$

\footnotetext{
4 The notion of monetary analysis as a "cross check" of economic analysis also implies that both approaches apply to the same policy-relevant time horizon (see, e.g., Jaeger 2003).

${ }^{5}$ The ECB is constantly working on improving its monetary analysis. For example, Papademos (2006, p. 4) points out that the ECB is carrying out research aimed at "...incorporating a richer financial sector into dynamic stochastic general equilibrium models, in order to study the role of financial variables in the conduct of monetary policy." He goes on to note that (p. 5) “...the monetary analysis of the ECB has evolved over time and is fairly comprehensive, going beyond the standard assessment based on the quantity theory of money and the stability of money demand." Beyond the improvements of the macroeconomic part of the monetary analysis, Papademos (2006, p. 6) also emphasis "the usefulness of monitoring and assessing monetary and credit developments...for the safeguarding of financial stability."
} 
In addition, monetary analysis takes a disaggregate perspective, focusing on other indicators of liquidity developments than M3. For instance, the ECB would carefully look not only at aggregate figures, but also scrutinize other monetary aggregates, private credit growth, as well as their counterparts in the aggregate balance sheet of monetary and financial institutions. As the ECB (1999) wrote, the general idea of looking beyond M3 was to provide useful "background information" for the assessment of aggregate developments - for example, to help separate transitory from price-relevant movements in monetary conditions.

These salient features of the ECB's monetary analysis have remained in place throughout its short history, but difficulties in implementation occurred early on, building pressure for changes in the framework. As Faruqee (2005) and de Haan and others (2005) describe in some detail, starting as early as 2000 , observed nominal M3 growth rates relative to the reference value were increasingly difficult to square with the interest rate decisions taken by the Governing Council. The ECB stressed in its communication that it had never intended to interpret the M3 reference value mechanistically and pointed to some of the specific disaggregate circumstances, such as portfolio shifts, that suggested that not all movements in M3 were likely to be price-relevant. But, for many, hearing these arguments "caused the impression that the ECB was looking for some kind of argument to ensure that developments under the first pillar were in line with the decision taken" (de Haan and others 2005, p.53).

As a consequence, ECB watchers took an increasingly critical view of the "monetary pillar" during this period. For instance, Cukierman (2001) stressed that a focus on inflation alone may provide for a more effective communication with the public. Bernanke and others (1999) also argued that inflation targeting is a communication device well-suited to establish and uphold a price-stability oriented reputation with economic agents even in the absence of an explicit monetary component. ${ }^{6}$ And Alesina and others (2001a, 2001b, p. 4) speaking about a "breakdown in communication," agreed that the ECB should abandon the two pillar approach in favor of a simple inflation targeting strategy. While they conceded that there may be good theoretical and empirical reasons why monetary aggregates may provide information about future euro-area inflation, they found it hard to "justify why it should be assigned any special role beyond that of a potentially useful leading indicator of inflationand, hence, an additional element in the ECB's current second pillar." That the ECB at times seemed to ignore M3 developments altogether when setting interest rates was recommendable, "but it should do it for the right reasons." Arguing a similar case, BiniSmaghi and Gros (2000, p.159) stated that "no clear explanation has been given about the operational role that such a monetary reference value should play in the ECB's strategy. It is obviously not an intermediate target, not even in the way that Bundesbank has intended it to serve in the past, that is, as a main explanatory factor for policy decisions."

During this period, the ECB and its staff maintained that the M3 reference value at the core of monetary analysis was valuable. For instance, Issing and others (2001) repeated the strong empirical relationship between long-run money growth and inflation and their theoretical

\footnotetext{
${ }^{6}$ More recently, Fatás and others (2007) showed that empirically any (and not just monetary) nominal target that is systematically achieved by the central bank is associated with low inflation.
} 
underpinnings, making it a crucial part of monetary analysis and, thus, any monetary policy strategy. Other arguments raised in support of the ECB's monetary strategy included the historical precedence of the Bundesbank's monetary policy regime and the necessity of some form of continuity in this regard (de Haan and others 2005). Finally, Issing (2001, p.23) stressed that, in the ECB's experience at least, monetary analysis had fared better than sometimes assumed: "the signals given by 'headline' growth rates of key monetary aggregates... have proven more reliable guides for monetary policy decisions than many external observers anticipated when the strategy was announced." But Issing also repeated that "the Governing Council has always clarified that it will not react in a mechanistic way to monetary developments and that a careful reading and analysis is always needed."

Nevertheless, acknowledging that the "two pillars" had posed "challenges for communication" (ECB 2003b, p.86), in May 2003 the ECB decided to refine its monetary strategy — and, in particular, monetary analysis. ${ }^{7}$ As the ECB (2003b, p.79) explained, while careful evaluation had "confirmed the main elements of the strategy originally announced in 1998," there was reason to "clarify to the public some aspects of the strategy." A first aspect was a more precise definition of the ECB's definition of price stability, which is now meant to imply inflation of below but "close to" 2 percent. The other pertained to the Governing Council's wish "to clarify communication on the cross-checking of information" on future price developments coming from the two elements of its monetary strategy.

As to monetary analysis, the 2003 changes stressed the medium- to long-term nature of the M3 reference value, put greater emphasis on the disaggregate perspective, and generally seemed to downgrade the relative importance of monetary analysis compared to its economic counterpart. Already the use of the word "cross-checking" signaled that the Governing Council intended to put its monetary and economic analysis on a more equal footing. In fact, by announcing a new structure of the introductory statement read by the ECB president to the media after Governing Council meetings, the Council seemed intent to reverse the previous order of the two aspects of its monetary strategy. Since 2003 the statement starts with the economic analysis identifying risks to price stability and only then turns to the monetary analysis, which now "mainly serves as a means of cross-checking, from a medium to longterm perspective, the short to medium-term indications coming from economic analysis" (ECB 2003a). However, with the ECB's (2003b, 2004) overall orientation at price stability over the medium-term, both remain relevant.

An important change underscoring the medium- to long-term nature of the reference value for monetary growth implemented in 2003 is that the Governing Council no longer reviews the reference value on an annual basis (ECB 2003a). The ECB (2003b, p.91) explained that this change was in line with the "medium-term nature" of the assumptions underlying the computation of the reference value since 1999. Presumably, the assumed stability of the money demand parameters and trends in velocity and potential output were then also responsible for the fact that the reference value had remained unchanged since 1999. However, the Council also signaled that it will update the reference value when necessary

\footnotetext{
${ }^{7}$ See also ECB (2003a) and Issing and others (2003).
} 
and remains committed to track monetary developments to identify medium- to long-term trends in inflation.

In addition, the ECB (2003b, p.89) stressed more the micro perspective of the monetary analysis. Citing a heightened need to distinguish "temporary phenomena" from more permanent changes in money demand, which it viewed "as a condition for setting a reference value for M3 growth", the ECB (2003b, p.91) announced an even more systematic monitoring of liquidity conditions beyond M3. The ECB pointed to M3 developments driven by increased asset price volatility and the resulting portfolio shifts into more liquid assets as an example for sizable yet probably temporary factors to be monitored in the future.

It seems clear, however, that the ECB's evaluation of its monetary analysis is ongoing along a number dimensions. For instance, judging by the steady flow of high-quality research conferences on relevant subjects and the publications of ECB and euro area central bank staff, there is a high interest in the theoretical underpinnings of the macroeconomic perspective. This interest includes empirical evidence on the validity of theories supporting the reference value approach. But there are also strong efforts to draw theoretical and empirical conclusion for monetary analysis from contemporaneous dynamic general equilibrium models. In Sections III and IV, we will discuss the ongoing theoretical and empirical debate along these lines.

\section{Survey OF THE TheORETICAL Debate}

There is an ongoing theoretical debate on the role of money in monetary policy. In the wake of the monetarist revolution, it seemed natural that central banks charged with keeping inflation at bay should be predominantly concerned with controlling money growth — or, more generally, with monetary analysis in terms of the ECB monetary strategy. However, modern macroeconomics in the New Keynesian tradition makes a strong case for focusing on interest rate setting alone (e.g., Clarida and others 1999, Woodford 2003). As Woodford (2007, p.14) argues, "there is nothing structurally incoherent about a [monetary] model that involves no role whatsoever for measures of the money supply." Based on this strand of the literature, the ECB should be focusing on its economic analysis alone. McCallum (2001), on the other hand, warns that the sheer fact that a model can be written without any direct reference to monetary aggregates does not mean that money should be ignored as a structural or informative factor for inflation, and there may be a number of reasons to suspect that the Woodford-type model may be over-simplified in this respect. The implication of McCallum's view, of course, would be that monetary policy may have a rationale to continue to pay attention to money.

In what follows, we survey the main aspects of this discussion, covering both general and partial equilibrium models. The survey reinforces some of the advantages of a general equilibrium approach, which provides, among other things, a more complete picture of the economy, allows the formulation of model-consistent forward-looking expectations, and shows greater robustness to the Lucas critique than partial approaches. Even more importantly, the development of generalized versions of the "cashless" New Keynesian standard model allows a unified treatment of essential monetary and non-monetary determinants of inflation in a consistent framework. This suggests that merging the two 
analytical pillars of the ECB's monetary strategy is a distinct and quite attractive possibility. In addition to freeing the arguments for a strong role of money in monetary policy from the confinement of partial equilibrium models, a unified analytical framework also helps focusing the debate on the relative weight of the economic and monetary factors. The survey also shows, however, that there is little hope to settle this issue on theoretical ground alone.

\section{A. The Cashless Benchmark: the Standard New Keynesian General Equilibrium Model}

In the cashless New Keynesian model (NKM), money plays little or no role for inflation and is introduced, if at all, more or less as an afterthought (see, among others, Galí and Gertler 2007). Central banks influence the economy only through the interest rate and its impact on consumption and investment decisions. And while interest rate control presupposes control of the money supply at the technical level, the central bank will supply money elastically at the set rate. As a consequence, aggregate output as well as the resulting time path of inflation is independent of the money supply. One way to characterize the cashless NKM in light of the ECB's monetary strategy would be to say that it focuses exclusively on important elements of its economic, non-monetary analysis.

To illustrate, consider a standard dynamic stochastic general equilibrium (DSGE) model as described, for instance, in Woodford (2003). The aggregate supply equation typically features a Calvo-style staggered price mechanism, where profit maximizing firms take into account the current output gap and expected future price developments when setting prices. Others may index prices to past inflation, a theoretical feature that helps the model to better capture some of the persistence found in real-world inflation data. In a log-linearized form around the steady state, the aggregate supply equation (or Phillips curve) then takes the form

$$
\hat{\pi}_{t}=\theta_{\pi} \hat{\pi}_{t-1}+\theta_{E \pi} E \hat{\pi}_{t+1}+\theta_{x} x_{t}+\varepsilon_{\pi, t}
$$

where $\hat{\pi}_{t}$ is the rate inflation, $x_{t}=y_{t}-y_{t}^{n}$ is the output gap, defined as the difference of output $y_{t}$ from its flexible-price (or natural) potential $y_{t}^{n}$, and $\varepsilon_{\pi, t}$ is a cost-push shock. ${ }^{8}$ The coefficients $0<\theta_{E \pi}<1, \theta_{\pi}, \theta_{\mathrm{X}}>0$ summarize deep structural parameters of the underlying micro-founded model and are, in principle, independent of the monetary policy regime. Finally, $E$ is the expectations operator, and it is assumed that expectations are formed in a way that is consistent with the full model and the period $t$ information set.

Aggregate demand is derived from household optimization based on a period utility function that, in the standard NKM, either excludes real money balances or includes them as a fully separable argument - a case we will discuss shortly. In both cases the Euler equation yields

$$
x_{t}=\phi_{E x} E x_{t+1}-\phi_{i}\left(\hat{i}_{t}-E \hat{\pi}_{t+1}\right)+\varepsilon_{x, t},
$$

\footnotetext{
${ }^{8}$ Unless otherwise stated, all variables in Sections III.A and III.B are defined as (log) deviations from the steady state marked by a “^”.
} 
where $\hat{i}_{t}$ is the nominal interest rate set by central bank and $\varepsilon_{x, t}$ is an aggregate demand shock. The coefficients $\phi>0$ summarize parameters in the representative household's utility function. The presence of the interest rate in the aggregate demand equation gives rise to the so-called interest rate channel, the core mechanism through which monetary policy influences the economy and, ultimately, inflation in the NKM.

Similar to the introduction of partial indexation in the Phillips curve, this formulation of the Euler equation is often extended to allow for habit persistence in consumption. The resulting introduction of additional leads and lags of the output gap (not shown) is said to greatly enhance the model's fit with the data (see, e.g., Fuhrer 2000, Christiano and others 2005).

Lastly, the central bank determines the nominal interest rate. In an optimal policy framework, the bank bases it decisions on a welfare function derived from the household utility under commitment. Alternatively, we may assume that it commits to follow a simple rule that links the time path of the interest rates to current and expected inflation and output gap. For instance, monetary policy could be following a Taylor-type rule of the form

$$
\hat{i}_{t}=\kappa_{i_{t-1}} \hat{i}_{t-1}+\left(1-\kappa_{i_{t-1}}\right)\left(\kappa_{\pi_{t}} \hat{\pi}_{t}+\kappa_{x_{t}} x_{t}\right),
$$

where the coefficients $\kappa>0$ are chosen so that the model's equilibrium is well defined. ${ }^{9}$

If equations $\left(1_{\mathrm{NKM}}\right),\left(2_{\mathrm{NKM}}\right)$, and $\left(3_{\mathrm{NKM}}\right)$ completely describe the equilibrium time path of output and inflation based on non-monetary or economic factors, what then is the role of money in this model class? As Woodford (2003) demonstrates, there are various ways of introducing money into the model without changing its core mechanism. For instance, households could face cash-in-advance constraints or employ money to reduce transactions costs for certain goods. Under some assumptions, this can be modeled by including real monetary balances as a separate argument into the period utility function. Then household optimization will, in addition to $\left(2_{\mathrm{NKM}}\right)$, yield a standard money demand function

$$
\hat{m}_{t}=\gamma_{y} \hat{y}_{t}-\gamma_{i} \hat{i}_{t}+\varepsilon_{m, t},
$$

with $\hat{m}_{t}$ and $\hat{y}_{t}$ representing the deviation of real monetary balances and output from their steady state levels, respectively, $\varepsilon_{m, \mathrm{t}}$ a liquidity preference shock, and where the coefficients $\gamma>0$ are based on parameters in the household's utility function.

\footnotetext{
${ }^{9}$ Equilibrium determinacy is discussed, for instance, in Woodford (2003). Also see Section III.B. Note that, except for the notation in deviations from the steady state, $\left(3_{\mathrm{NKM}}\right)$ is similar to a forward-looking Taylor rule with inertia, where the central bank reacts to deviations of inflation from its inflation target (assumed to be identical with the steady state) and the output gap from its steady state (assumed to compatible with the inflation target).
} 
But while the NKM can be amended to explain the demand for monetary balances, money performs no function of relevance from a policy perspective. Given equations $\left(1_{\mathrm{NKM}}\right)$, $\left(2_{\mathrm{NKM}}\right)$, and $\left(3_{\mathrm{NKM}}\right)$, money has no structural or causal role to play in determining the equilibrium time path of inflation. In addition, money is also denied any informational function. As Woodford (2007) carefully points out, the time path of real balances described in $\left(4_{\mathrm{NKM}}\right)$ is merely a reflection of contemporaneous developments elsewhere in the economy distorted by a money demand shock.

It is important to note that the neutrality of money with regard to inflation extends to the long-run - which reinforces the relevance of the result for the ECB's current monetary strategy. The ECB (2003b, p.87) stresses that its monetary analysis is focused predominantly on the medium- to long-run and asserts that there is a close association between the "more drawn out and persistent trends" in inflation and the "medium- to long-run trend of money growth." ${ }^{10}$ However, as Woodford (2008) illustrates in some detail, the NKM model with added money demand implies a long-run correlation between money and inflation (which are both endogenous variables in the model) despite the absence of a causal or structural relationship. In other words, while the New Keynesian DSGE model is tuned to short- to medium-term business cycle frequencies, its implications include the longer run. (Of course, a corollary of this is that any causal or informational role of money for inflation that could be established within the NKM framework - see Section III.B below-would not only be relevant in the long-run but also at shorter-run business cycle time horizons.)

As a consequence, the policy recommendation stemming from the cashless NKM is that central banks would be well-advised to ignore monetary developments altogether. Conditioning monetary policy on monetary developments - e.g. by including money in one form or another in the Taylor-type rule $\left(3_{\mathrm{NKM}}\right)$ - will do little to improve the central bank's control over inflation. On the contrary, because money demand is subject to shocks, conditioning interest rates on monetary developments would add unwanted volatility to the economy. Taken literally, the implication for the ECB's monetary strategy would be to forgo monetary analysis and focus on economic analysis alone.

\section{B. The Case for Money in the Generalized New Keynesian Model}

The policy recommendations based on the NKM approach could hardly be more straightforward - but then, or so some argue, the standard model may not be a good description of a monetary economy. In what follows, we will review some of the key arguments made for a more prominent role of money, including non-separability and financial frictions, which give money a causal or structural role in the economy. Another argument could be equilibrium indeterminacy. Finally, the NKM model can be amended in various ways to show that money could have an important informative function for monetary policy.

\footnotetext{
${ }^{10}$ Fischer and others (2008) stress that the ECB's Quarterly Monetary Assessment is mostly (albeit not exclusively) targeted at medium- to long-term inflation forecasting. See also the background study by Masuch and others (2003).
} 


\section{Non-separability: money and the interest rate channel}

Those arguing in favor of a more prominent role of money often stress the lack of generality of the NKM, and a fairly direct approach to generalization is to lift the separability assumption of the household utility function. As, among others, Nelson (2002) and Ireland (2004) have shown, introducing non-separability of money and consumption will introduce a causal link from monetary aggregates to the output gap and inflation. ${ }^{11}$ From the perspective of the ECB's monetary strategy, this effectively integrates elements of monetary and economic analysis in one unified analytical framework.

With the separability assumption lifted, money influences inflation through two channels. Real balances now enter as an argument into the dynamic demand equation because they influence the household's consumption decisions. For the same reason, money enters the stochastic discount factor of price-setting firms and, thus, the dynamic supply equation. ${ }^{12}$ As Andrés and others $(2006)$ show, instead of $\left(1_{\mathrm{NKM}}\right)$ and $\left(2_{\mathrm{NKM}}\right)$ in the NKM we then have

$$
\begin{gathered}
\hat{\pi}_{t}=\widetilde{\theta}_{\pi} \hat{\pi}_{t-1}+\widetilde{\theta}_{E \pi} E \hat{\pi}_{t+1}+\widetilde{\theta}_{x} x_{t}-\widetilde{\theta}_{m} \hat{m}_{t}+\varepsilon_{\pi, t} \\
x_{t}=\widetilde{\phi}_{E x} E x_{t+1}-\widetilde{\phi}_{i}\left(\hat{i}_{t}-E \hat{\pi}_{t+1}\right)+\widetilde{\phi}_{m} \hat{m}_{t}-\widetilde{\phi}_{E m} E \hat{m}_{t+1}+\varepsilon_{x, t}
\end{gathered}
$$

with $0<\widetilde{\theta}_{E \pi}<1, \widetilde{\theta}_{\pi}, \widetilde{\theta}_{x}, \widetilde{\theta}_{m}>0$, and all $\widetilde{\phi}>0 .{ }^{13}$ Household optimization will also yield a standard money demand function comparable in form to equation $\left(4_{\mathrm{NKM}}\right)$. Finally, to close the model, a plausible assumption is that the central bank takes into account that money now plays a causal role in the economy when setting interest rates. To that end, one can define a Taylor-type rule

$$
\hat{i}_{t}=\widetilde{\kappa}_{i_{t-1}} \hat{i}_{t-1}+\left(1-\widetilde{\kappa}_{i_{t-1}}\right)\left(\widetilde{\kappa}_{\pi_{t}} \hat{\pi}_{t}+\widetilde{\kappa}_{x_{t}} \hat{x}_{t}+\widetilde{\kappa}_{M_{t}} \hat{M}_{t}\right),
$$

\footnotetext{
${ }^{11}$ As far as the aggregate implications are concerned, the non-separability argument is conceptually close the idea that real monetary balances have a direct demand effect in the tradition of Pigou and Patinkin. Ireland (2001) develops a real balance effect in a cash-in-advance DSGE framework under separable utility. However, the real balance effect has been met with skepticism, owing, in part, to the dominance of non-money holdings in private wealth and the fact that outside money (i.e. currency in circulation) is only a small fraction of monetary aggregates (see Nelson 2003, Brand and others 2003). The Bundesbank (2005) summarizes the evidence on the real balance model as weak at best for the U.S., the U.K., and the euro area as a whole.

${ }^{12}$ Note that - assuming a standard household utility function $u($.$) with u_{c}, u_{m}>0, u_{c c}, u_{m m}<0$, and $u_{c m}>0-$ the direct and indirect impact of contemporaneous money on inflation move into opposite directions, with the overall impact being a question of the underlying parameters and, thus, ultimately an empirical matter.

${ }^{13}$ A variant of the above model introduces, in addition, non-separability across period - that is, habit persistence in consumption. Andrés and others (2007) show that this adds inertia to output and inflation, and money demand conveys forward-looking information on output similar to what we discuss in Section III.B around equation $\left(4_{\mathrm{NKMA}}\right)$.
} 
where $\hat{M}_{t}$ represents the deviation of nominal balances from their steady state value, and where the $\widetilde{\kappa}>0$ guarantee a well-defined equilibrium (see Rudebusch and Svensson 2002, Nelson 2003, Andrés and others 2006).

While a relatively straightforward way to ensure money a causal role as a determinant of inflation in a generalized NKM approach, non-separability is rarely considered a strong argument among theorists. McCallum (2001) argues that non-separability effects tend to be small under plausible specifications of the utility function. Woodford (2003) comes to similar conclusions in his discussion of the "cashless limiting economy". The basic idea is that, while money may influence marginal utility from consumption, it is usually required for only a small fraction of transactions. In the limit, the non-separability argument can therefore be neglected.

The small empirical literature on money separability also sends ambivalent signals. Kremer and others (2003) estimate a structural NKM model for German data using a Bayesian approach and find evidence for the non-separability of money and consumption. These results are at odds with the negative findings of Ireland (2004) for the U.S. and Andrés and others (2006) for the euro area, suggesting that there may be cross-country differences to take into account. ${ }^{14}$ Jones and Stracca (2006) provide more mixed evidence employing a nonparametric approach. They find that additive separability cannot be rejected for their full sample period 1991-2005 in the euro area. On the other hand, this result seems to be driven by a small number of observations, which to the authors suggests that additive separability holds "most of the time" (Jones and Stracca 2006, p.6). They speculate that additive separability could be regime-dependent, prevailing mostly in credible low-inflation environments.

Overall, this suggest that non-separability provides a qualitatively interesting but quantitatively not compelling reason for integrating monetary factors into the cashless standard NKM. The question is whether additional arguments can be mustered to strengthen the case for money in the analytical framework.

\section{Information: money as an indicator}

Another argument brought forward to underline the relevance of money in monetary policy is that of informational frictions. The general idea is that money may complement the information set of policy makers seeking to control inflation no matter whether it has a structural or causal role to play in the economy or not. In what follows, we first discuss the general issue whether money can provide relevant real-time information for policy makers. In the next step we return to general equilibrium modeling to take a closer look at the idea that money could, perhaps in addition, reveal crucial forward-looking information. From the viewpoint of the $\mathrm{ECB}$, the information content of money captured in the latter approach

\footnotetext{
${ }^{14}$ The Kremer and others (2003) results are more pronounced in some time samples than others. Also note that their solution technique deviates from Ireland (2004) and Andrés and others (2006) in that it does not force a non-explosive solution in the Taylor-type rule.
} 
could be a further reason to integrate monetary and economic analysis in one analytical framework.

\section{Observability: money as a source of real-time information}

Nelson (2002), following earlier ideas by Meltzer (2001), points out that money may be a superior index of monetary policy effects than the interest rate. The basic argument is that money demand is a function of various asset yields (e.g., interest rates of all terms, yields of real assets such as housing, share yields, the exchange rate, etc.) as well as of unobservable yields to human capital. As a consequence, monetary aggregates will reflect (equilibrium) changes of these asset prices and, thus, provide important information to monetary policy beyond what can be captured by a specific short-term rate. In particular, if the various asset prices shaping money demand are also relevant for consumption and investment decisions, real money balances could also be a good indicator of the overall policy stance. ${ }^{15}$

Monetary aggregates may also have important real time informational content within a standard NKM framework with a traditional money demand function. For instance, it has been said that money can serve as a real time indicator of real GDP growth, which is observed with significant lags and subject to (often significant) data revisions (Bundesbank 2005, Masuch and others 2003). Output data is revised substantially for a period of up to nine month after their first release, while monetary (like price) data are subject to only minor revisions within a short period after release. Thus, as Coenen and others (2005) conclude, monetary aggregates could have a significant role in providing information about the current level of aggregate demand and therefore about the resulting pressures on inflation. ${ }^{16}$ This also seems to play some role in practice (Calza and others 2001). Fischer and others (2008, p.5) report that the ECB looks to short-run money demand dynamics to complement its economic analysis: for instance, "money demand equations might suggest that strong monetary growth was a result of strong real income growth and/or a low level of interest rates in the economy. Strong monetary dynamics would thus be seen as confirmation of signals coming from conjunctural indicators."

However, the real-time informational content of monetary aggregates is not undisputed. At a theoretical level, Galí (2008) argues that the information contained in monetary aggregates can be misleading. For example, consider a simple economy blessed with a productivity boom that was fully accommodated by output growth. In such a scenario, output growth would prompt an increase in money demand that could be taken to signal upward inflation pressure. However, with the output gap unchanged, inflation would likely remain constant. ${ }^{17}$

\footnotetext{
${ }^{15}$ See also Brand and others (2003). Masuch and others (2003) discuss empirical evidence supporting the view that the money stock serves as a proxy for a spectrum of interest rates. As Nelson (2002) shows, the adjustmentcost approach discussed below can be interpreted as a simple formalization of this idea within a DSGE model.

${ }^{16}$ Svensson (2003, p.1070), too, calls the idea of money as an indicator variable "the potentially most useful role for money in monetary policy analysis." See also Smets (2003).

${ }^{17}$ Stepping outside the DSGE approach, he looks at a simple economy with a Phillips curve and a standard money demand function. If the productivity increase was fully accommodated by output growth, inflation would remain constant but the money stock would (still) increase.
} 
He concludes that a stable money demand relationship does not imply that monetary indicators are useful in assessing inflation risks.

An additional problem is the (in)stability of money demand, which can introduce a Pool-type tradeoff between the relative variances of money demand shocks and output mismeasurements (Coenen and others 2005, Dotsey and Hornstein 2003). More specifically, while there may be reason to believe that, as a rule, real money demand reflects the true level of output because households have full information over individual private income, the underlying household preferences for liquidity may be subject to temporary changes. And even the Bundesbank (2005, p.21) concedes that "the degree of inaccuracy in measuring GDP appears to be relatively small in relation to an indirect observation via money growth."

Finally, the informational advantages of monetary aggregates are disputed from a practical viewpoint as well. One argument is based on the observation that alternative measures of real activity other than GDP are readily and timely available (Galí and others 2004). What is more, the computation of usable figures for monetary aggregates at higher frequencies requires a number of interventions, too. For instance, the ECB, just as the Bank of England or the Bundesbank, corrects the monthly level of monetary aggregates for seasonality, end-ofmonth effects, reclassifications (e.g., the enlargements of the euro area in 2001 and 2007), and revaluations (Fischer and others 2008, Appendix C). ${ }^{18}$

\section{Information biases: money as a Phillips curve cross-check}

Despite these issues, Beck and Wieland (2007a) argue that the real-time observability of money could help policy makers reduce uncertainty about the true time path of potential output. The basic idea is that - through a standard money demand function - the long-run component of money growth is correlated with the long-run component of output growth and, thus, or so the authors argue, the growth rate of potential output. ${ }^{19}$ As a consequence, long-run money growth can be used to "cross check" inflation forecasts based on non-monetary factors and correct any permanent information gap or structural bias of the central bank with regard to the output gap argument in its policy rule.

More specifically, the authors suggest that the central bank adjusts its interest rate upward whenever the (appropriately filtered) long-run component of money growth in excess of observed long-run output growth (weighted by the output elasticity of money demand) exceeds a critical threshold anchored by the inflation target. If inflation remains below this threshold, the interest rate follows a conventional Taylor-type rule based on observed inflation and the output gap. In a simulation exercise using a (backward-looking) DSGE

\footnotetext{
${ }^{18}$ Fischer and others (2008) also document at some length how the increasing importance of portfolio-related changes for the development of monetary aggregates from the year 2001 onward have reduced the usefulness of mechanical money demand functions for the ECB's Quarterly Monetary Assessment. See Section V for a more detailed discussion.

${ }^{19}$ Also see Orphanides (2003). The concept of potential output in current New Keynesian DSGE models is not necessarily identical with the long-run trend of output. See, for example, Clarida and others (1999) and Woodford (2003) for a discussion.
} 
model calibrated to the euro-area economy they show that - under the assumption the central bank does indeed persistently misjudge the output gap - an interest rate rule based on the idea of cross-checking can produces sizable stability gains.

While intriguing, the cross-checking idea can be questioned along a number of dimensions. Obviously, cross checking requires long-run monetary developments to be correctly identified, which demands a suitable amount of data (see also the discussion of the two-pillar Phillips curve in Section III.C below). Moreover, it is not entirely clear why the central bank does not directly exploit excess long-run money growth to directly improve its estimate of the output gap. In addition, Galí and others (2004, p. 27-29) remark that the ECB need not observe the development of monetary aggregates to receive information whether policy has gone off track - it can directly observe the price level instead. And while information on the price level may be slower in arriving than monetary data, it is very likely available early enough to allow accurate identification of medium- or long-term trends in time to alter them. Finally, the question arises whether the assumption of more or less permanent information impairment on the side of the central bank is the most straightforward way to introduce an important informational function for money. For instance, the Andrés and others (2007) model discussed below makes a similar case for money based on the assumption that household money demand is forward-looking.

\section{Adjustment costs: money as a source of forward-looking information}

In addition to their potential real-time information qualities, monetary aggregates may also be a forward-looking indicator of economic activity - a quality that may be of particular value to policy makers. Nelson $(2002,2003)$ argues that monetary aggregates will anticipate interest rates and output - and, by extension, also inflation - if money demand was forwardlooking. ${ }^{20}$ This will be the case in the presence of adjustment costs for real balances because already small adjustment costs give cash-holding households an incentive to smooth their stock of real monetary balances over time. ${ }^{21}$

This idea can be incorporated in the standard NKM model discussed in Section III.A, while otherwise keeping the framework $\left(1_{\mathrm{NKM}}\right)$ and $\left(2_{\mathrm{NKM}}\right)$ intact. Andrés and others $(2007)$ show that in this case real money demand becomes

$$
\hat{m}_{t}=\bar{\gamma}_{y} \hat{y}_{t}-\bar{\gamma}_{i} \hat{i}_{t}+\bar{\gamma}_{m} \hat{m}_{t-1}+\bar{\gamma}_{E m} E \hat{m}_{t+1}+\varepsilon_{m, t}
$$

\footnotetext{
${ }^{20}$ Given potential output, the link to inflation would be provided by a dynamic AS-equation such as $\left(1_{\mathrm{NKM}}\right)$ see above. The fact that monetary policy involves complex transmission processes, including port-folio rebalancing, has also recently been stressed by Goodfriend (2000).

${ }^{21}$ Note that a simple cash-in-advance constraint of the form $M_{t-1} / P_{t-1}>Y_{t}$ (with $P$ indicating the price level and $M$ the nominal level of money stocks) would, in principle, also create forward-looking behavior of households or investors. The standard assumption is $M_{t} / P_{t}>Y_{t}$, which is mimicked by money-in-utility frameworks where the contemporaneous money stock enters the utility function (see Section III.A above).
} 
where all $\bar{\gamma}>0$ and $\varepsilon_{m, t}$ is a money demand shock stemming from household preferences. Note that money demand is now influenced by lagged as well as expected real balances, the latter of which implies that it will reflect the entire expected future time path of interest rates and output. ${ }^{22}$ Nelson (2003) then argues that in the presence of informational frictions-for instance, if current private sector shocks are unknown to the central bank (see Aoki 2006) incorporating money into the policy function along the lines of $\left(3_{\text {NKMS }}\right)$ will be optimal. ${ }^{23}$ While this will also hold in the absence of adjustment costs, the weight given to monetary aggregates in the policy rule is particularly large when money demand is forward-looking.

Andrés and others (2007) produce evidence that a model along the lines of $\left(1_{\mathrm{NKM}}\right),\left(2_{\mathrm{NKM}}\right)$, $\left(3_{\mathrm{NKMS}}\right)$, and $\left(4_{\mathrm{NKMA}}\right)$ provides a reasonably good fit of the euro-area and U.S. economies. Like the non-separability result discussed in Section III.B, this seems to suggest that the standard NKM model may indeed be somewhat less general-and the role of money somewhat more prominent - than often thought. ${ }^{24}$ Of course, some of the arguments mentioned earlier with regard to real time information still apply. For instance, the information content of money would be diminished in the presence of strong money demand shocks.

In summary, it would seem that the information angle has the potential to add to the nonseparability argument in support for a prominent role of money in monetary policy in principle. However, the discussion of the extent of its quantitative relevance has only just begun.

\section{Financial frictions: money and the credit channel}

The absence of an explicitly modeled monetary transition mechanism including money-in particular one that involves banks and credit supply - is another of the principal criticisms of the cashless NKM approach. Prominent examples for DSGE models including such mechanisms can be found in the credit channel literature (Bernanke and Gertler 1995). ${ }^{25}$ The

\footnotetext{
${ }^{22}$ Habit persistence in consumption would further enrich the dynamics of (4NKMA). As Nelson (2002) notes, one interpretation of the equation is that it illustrates the dependence of money demand on long-run asset prices (i.e. interest rates) in the spirit of Meltzer's (2001) argument discussed earlier. See Coenen and others (2005) for a related discussion.

${ }^{23}$ In general, this will also hold for a policy rule conditioning the interest rate on expected inflation. Assume, for instance, the central bank does not observe the output gap. Based on $\left(1_{\mathrm{NKMS}}\right)$, neither current inflation nor expected inflation will be perfectly correlated with the output gap. Thus money is always likely to add to the central bank's information set because, just like the output gap itself, it depends on the future time path of interest rates (see also Nelson 2002).

${ }^{24}$ In a broadly related result, Leeper and Roush (2003) find that adding a monetary argument to the interest rates equation improves the fit of empirical impulse responses to monetary shocks for U.S. data (see, e.g., Leeper and others 1996 and Christiano and others 1998 for earlier work). Smets (2003) interprets this as supporting the informational content of money.

${ }^{25}$ Also see, for instance, recent contributions from Christiano and Rostagno (2001), Christiano and others (2005), and Goodfriend and McCallum (2007).
} 
basic idea is that banks and financial markets fulfill a crucial function in investment financing in the presence of information asymmetries. This function can give rise to an additional transition channel that complements the interest rate mechanism at the heart of the NKM approach. Similar to the interest rate channel, the credit channel's influence on inflation is an indirect one working through the demand side and, ultimately, the output gap.

The credit channel is often broken down into two separate mechanisms: the traditional banklending and the balance-sheet channel. The bank-lending channel emphasizes that monetary policy influences the real economy though bank loan supply, which depends to a large degree on the banks' ability to draw demand deposits. Money matters in this regard because the availability of demand deposits is influenced by the supply of central bank liquidity or money (Bernanke and Blinder 1988). The link exists, for instance, if there are binding reserve requirements for banks or because the supply of central bank liquidity influences the ability of banks to attract nominal demand deposits. Banks may be interested in attracting nominal deposits since they allow them to share profit risk associated with real shocks with depositors (Diamond and Rajan 2001, 2006).

The other relevant mechanism is the so-called financial accelerator or balance-sheet channel, describing the way credit markets can amplify the effects of monetary policy. Behind this is the fact that the external finance premium paid by borrowers is a negative function of the value of the collateral (i.e. their balance sheet) required by banks, which, in turn, depends on the interest rate set by the central bank. For instance, a policy interest rate hike that worsens the balance sheet positions of firms will cause external borrowing costs to increase, which can limit firms' ability to invest over and beyond the immediate impact of the initial policy measure (Bernanke and others 1996). Note that, to the extent that banks use external sources of finance instead of demand deposits to extend credit, they may themselves be subject to balance-sheet effects. In this case borrowers are likely to see any change in the banks' external finance premium reflected in their credit costs, which will also reduce their ability to invest.

The credit channel clearly indicates a role for money in the transmission process of monetary policy - but the extent to which this is the case is under some dispute. As to the balance sheet or financial accelerator channel, Greiber and Setzer (2007, p.5) argue that money may play some role as an indicator variable, since "[i]n a rather mechanical sense the creation of a new loan is likely to go along with the creation of new deposits." However, Galí and others (2004) stress that the balance sheets of households and firms or solvency indicators of the banking system should be more important state variables than the growth of monetary aggregates.

And even for the bank-lending channel, where money has a more central function by construction, its relevance has been questioned. One issue is the reduction in the importance of bank lending in more advanced financial markets. As Bernanke (2007) points out, the development of financial markets tends to go along with an increase in market-based financing, which reduces the relevance of the bank-lending channel and, by extension, of central bank liquidity. But even in the presence of strong bank-based financing, more 
developed financial market will tend to reduce the importance of money because banks get access to other sources of liquidity and depend less on demand deposits. ${ }^{26}$ This does not necessarily mean that financial development makes the credit channel obsolete. As already mentioned, there may be non-traditional credit channel effects operating through bank balance sheets. ${ }^{27}$ Overall, however, it would seem that the traditional money-based credit channel is destined to gradually loose significance even in still relatively bank-based financial systems such as the euro area.

And indeed, summarizing the exhaustive research effort of the Eurosystem's monetary transmission network for the euro area, Angeloni and others (2002, p.44) write that "the overall role of banks in the transmission mechanism is somewhat different, and perhaps smaller, than what might have been expected based on prior work." The interest rate channel seems to explain most of the reaction of the euro-area economies to monetary policy. And, even though there is some evidence that credit supply changes with monetary policy, these effects vary largely with the liquidity position of banks and are not uniform across euro-area member countries (e.g., Ehrmann and others 2003). ${ }^{28}$

This suggests that the credit channel argument adds some support to non-separability and information in justifying a significant position for monetary factors in monetary policy overall. However, this support is very limited.

\section{Equilibrium selection: money and the price level}

Finally, at a more technical level, another argument in favor of a prominent role for money in monetary policy could be equilibrium indeterminacy in DSGE models. In a classical contribution, Sargent and Wallace (1975) argued that an interest rate rule may leave the economy's price level indeterminate if the interest rate policy rule reacts to the history of exogenous disturbances only. McCallum (1981) later pointed out that money could provide a solution. He stressed that the central bank could anchor the economy and avoid any unwanted volatility caused by multiple equilibria by conditioning the interest rate, in addition, to monetary developments.

There is, however, some debate whether this result extends to modern DSGE models. Woodford (2003) argues against money as a unique anchor, pointing out that, in principle,

\footnotetext{
${ }^{26}$ The same holds for the reduction in the stringency of reserve requirements. For the U.S. case, Loutskina and Strahan (2008) show empirically how financial innovation, in particular securitization, has reduced the impact of lending conditions set by monetary policy on credit supply.

${ }^{27}$ See Bernanke (2007). Making a related point, Van den Heuvel (2007) models bank lending in the presence of capital adequacy regulations but without reserve requirements. The results imply lending will depend, among other things, on banks' financial structure and interest rates.

${ }^{28}$ On the financial accelerator, Greiber and Setzer (2007) and Bundesbank (2007) report that expansionary monetary conditions have positive feedback effects on housing prices, which Greiber and Setzer (2007, p.2) take to imply that "a stronger case can be made for ... the indicator properties of money". See, however, the discussion above.
} 
any commitment to a real or nominal endogenous state variable can anchor the economy's price level locally around the steady state. ${ }^{29}$ For instance, an interest rate rule of the type $\left(3_{\mathrm{NKM}}\right)$, while not including a monetary argument, will still determine the price level if the central bank's reaction to the output gap and the rate of inflation are correctly chosen, that is, if a version of the so-called Taylor principle holds. ${ }^{30}$ However, Christiano and others (2008) illustrate that small changes in the NKM approach, such as introducing a real cost (or supplyside) channel of interest rates, can re-introduce indeterminacy. ${ }^{31}$ In this case, money may play an important role in the sense of an escape clause: if economic variables fluctuate in response to non-fundamental (or expectation) shocks, abandoning the Taylor-type rule in favor of a policy strategy stabilizing the money stock can be beneficial.

But there remain doubts whether indeterminacy indeed robustly supports a money-based monetary strategy. As Christiano and others (2008) readily concede, for instance, stabilizing any other economic variable under the escape clause would serve the same purpose as stabilizing the money supply. The argument has to be made that the central bank can indeed control the relevant monetary aggregate better than any other variable in the economy. ${ }^{32}$ Moreover, as Uhlig (2008) argues, the type of boom-and-bust cycles the money-based escape clause strategy could prevent may not be empirically relevant. Finally, from a theoretical perspective, other principles of equilibrium selection on the basis of learning dynamics (Lucas 1986) may also shape the relevance of the issue. For example, McCallum (2003) qualifies multiple equilibria as theoretical curiosities with little relevance for actual economies, and that can be overcome by the adaptive learnability of the bubble-free solution. ${ }^{33}$

\footnotetext{
${ }^{29}$ McCallum (2001), von Hagen (2004), and Masuch and others (2003), among others, make similar points.

${ }^{30}$ As Woodford (2003) shows, the determinacy conditions may involve both lower- and upper-bounds for the reaction to state variables if the Taylor-type rule is forward-looking and the $\kappa \geq 0$.

${ }^{31}$ See also Christiano and Rostagno (2001), Benhabib and others (2001a), and Carlstrom and Fuerst (2002). As Christiano and others (2008) explain, balance-sheet effects along the lines previously discussed could also be part of the supply-side impact of interest rates.
}

${ }^{32}$ Galí and others (2004, p.31) stress that rules that bind the central bank's nominal policy rate to endogenous variables, including real variables, can be interpreted as a commitment to as money supply target - albeit one that excludes money: "A commitment to a money-supply target implies a commitment to raise nominal interest rates at a certain rate in response to increases in the general level of prices above that characteristic for the optimal equilibrium, and similarly to raise interest rates in response to increases in real activity; otherwise, the central bank would be accommodating the increased money demand that would result from increases in either prices or real activity."

${ }^{33}$ Similar conclusions seem to hold for the related debate on multiple global equilbria. As, for instance, Benhabib and other (2001a, 2001b) demonstrate, local determinacy may go hand-in-hand with global indeterminacy - for instance, in the case of a self-fulfilling deflationary trap where the nominal interest rate drops to its zero lower bound. However, Woodford (2003) argues that some plausible learning processes can ensure that the forces anchoring the locally stable equilibrium also anchor the global equilibrium if shocks to expectations are not too large. Moreover, the problem of globally indeterminate equilibria is not confined to Taylor-type rules and can also occur under monetary strategies based on money targeting. 


\section{The Case for Money in Partial Equilibrium Models}

Leaving the realm of DSGE models, there is an interesting partial-equilibrium literature focusing on the contribution of money as a direct determinant of inflation. While severely criticized for their less-than-complete description of the underlying economic forces, partial equilibrium models are not without theoretical background (inspired by the quantity theory of money) and often appear well-anchored in empirical research (stressing the long-run correlation of money and inflation). In addition, they seem to be popular among practitioners of central banking. From the mainly theoretical perspective entertained in the present section, however, the main question is whether partial equilibrium models add to list of arguments discussed in Section III.B. With that in mind, we will describe the two core models in this domain.

\section{The P* model: money and the price level}

A well-known approach motivated by the quantity theory of money is the so-called P-star (or $\left.\mathrm{P}^{*}\right)$ model favored by some economists and central bank practitioners. ${ }^{34}$ Starting point of the $\mathrm{P}^{*}$ model is the assumption that deviations of the (log of the) actual price level, $p$, from the equilibrium price level, $p^{*}$, the so-called price gap, can be used to predict future price adjustments and, thus, inflation. ${ }^{35}$ Based on Svensson (2000), this can be illustrated using a simple version of the Phillips curve such as

$$
\pi_{t}=\alpha_{\pi} \pi_{t-1}+\alpha_{E \pi} E \pi_{t+1}+\alpha_{P^{*}}\left(p_{t-1}^{*}-p_{t-1}\right)+\varepsilon_{\pi, t}
$$

where all $\alpha>0 .{ }^{36}$ Note that the $\mathrm{P}^{*}$ model does not restrict the expectations term, which, in principle, could take any form.

Following Gerlach and Svensson (2003), the price gap can be related to the monetary gap or excess liquidity, defined as the difference between the real money stock and its equilibrium level, $m_{t}^{*} \equiv m_{t}-p_{t}^{*}$. That is,

$$
p_{t}^{*}-p_{t}=m_{t}-m_{t}^{*}
$$

Reynard (2007), alluding to the quantity theory of money, defines $p^{*}$ as the equilibrium price level supported by the current nominal quantity of money in circulation, $M_{t}$, given potential output and the equilibrium velocity, $v_{t}^{*}($ all in $\log s)$,

\footnotetext{
${ }^{34}$ See, among others, Hallman and others (1991), Tödter and Reimers (1997), Neumann (1997), Orphanides and Porter (2000), and Masuch and others (2001).

${ }^{35}$ Unless otherwise stated, all variables in Section III.C are defined as (log) levels.

${ }^{36}$ Equation (1) nests a number of $\mathrm{P}^{*}$ approaches. Hallman and others (1991), for instance, assume $\alpha=1$, which seems to be in line with Reynard's (2007) empirical observation that the price gap influences inflation with considerable lags and some persistence.
} 


$$
p_{t}^{*} \equiv c+M_{t}+v_{t}^{*}-y_{t}^{*}
$$

where $c$ is a constant. In line with Orphanides and Porter (2000), $v_{t}^{*}$ can be modeled as $v_{t}^{*}=\eta i_{t}^{*}$, where $i_{t}^{*}$ is the level of the equilibrium short-term interest rate proxying the opportunity costs of money holdings and $\eta>0$ is the semi-elasticity of money demand with regard to $i_{t}^{*}$. This implies that the $\mathrm{P} *$ inflation process involving money is a function of the excess of real balances over equilibrium money demand:

$$
\pi_{t}=\widetilde{c}+\alpha_{\pi} \pi_{t-1}+\alpha_{E \pi} E \pi_{t+1}+\alpha_{P^{*}}\left(m_{t-1}+\eta i_{t-1}^{*}-y_{t-1}^{*}\right)+\varepsilon_{t, \pi}
$$

with $\widetilde{c}=\alpha_{P^{*}} c>0$.

Versions of the $\mathrm{P}^{*}$ model are reported to do well in some empirical applications (e.g. Masuch and others 2001), but the approach also has no lack of critics. On the empirical level, Reynard (2007) and Nelson (2007) have pointed to the difficulties of identifying equilibrium changes in velocity in a plausible manner. And Gerlach and Svensson (2003, p.1653) rather bluntly state that "the microfoundations of the $\mathrm{P}$ * model are not clear (to us, at least)...," a sentiment echoed by André and others (2007). But perhaps the most interesting observation is that, at least to some extent, equation $\left(1_{\mathrm{P} *}\right)$ resembles the Phillips curve under the generalized New Keynesian DSGE model allowing for non-separability in Section III.B). Both equation ( $\left.1_{\mathrm{P}^{*}}\right)$ and $\left(1_{\mathrm{NKMS}}\right)$ add a monetary factor to an otherwise traditional Phillips curve, even though this factor takes the form of the deviation of the money stock from its steady state level and equation $\left(1_{\mathrm{P}^{*}}\right)$ focuses on excess demand.

However, if the principal idea of money directly influencing inflation can be plausibly expressed in either a partial or a general equilibrium approach, the latter holds a number of advantages. Clearly, an DSGE model gives a more complete and ultimately more informative picture of money's potential role in the economy. While the $\mathrm{P} *$ model postulates that the impact of money can be captured by the Phillips curve alone, the Phillips curve in the DSGE model describes only one of two channels through which money impacts inflation. ${ }^{37}$ Moreover, its micro-foundations make the DSGE model less prone to parameter instability in structural empirical applications - a particularly attractive feature for policy makers who are interested in predicting the impact of policy changes (see, e.g., Lubik and Surico 2006, Woodford 2008).

Among other things, these observations suggest that the $\mathrm{P} *$ model adds little to the arguments in favor of a more prominent role of money listed in Section III.B.

\footnotetext{
${ }^{37}$ As discussed, the other channel works through the demand (or Euler) equation ( $2_{\mathrm{NKMS}}$ ), and both interact in the general equilibrium. In addition, the parameters in $\left(1_{\mathrm{NKMS}}\right)$ are structural in nature.
} 


\section{The two-pillar Phillips curve: money and long-run inflation}

Another prominent partial-equilibrium approach is the two-pillar Phillips curve, developed most recently in a series of papers by Gerlach (2004) and Assenmacher-Wesche and Gerlach (2006a, 2006b). ${ }^{38}$ This strand of the literature focuses on the "trend", "core", or "lowfrequency" movements (i.e. movements that continue long enough un-reversed to qualify as a long-term depending on a particular definition) of money. Similar to the price gap discussed above, these long-run movements in money growth are added as a "second pillar"- - a term explicitly linking this approach to the ECB's self-description of its monetary analysis - to a conventional Phillips curve approach.

Somewhat more formally Assenmacher-Wesche and Gerlach (2006a, 2006b) describe the two-pillar approach as

$$
\pi_{t}=\beta_{\pi} \pi_{t-1}+\beta_{x} x_{t}+\beta_{m}\left(\Delta m_{t}^{L}+\tau \Delta i_{t}^{L}-\Delta y_{t}^{L}\right)+\varepsilon_{\pi, t}
$$

with all $\beta, \tau>0$, and where $\Delta m_{t}^{L}, \Delta y_{t}^{L}$, and $\Delta i_{t}^{L}$ represent the growth rate of the long-term component of real money balances, real GDP growth, and the nominal interest rate change, respectively. The expression in parenthesis on the right-hand-side of equation $\left(1_{2 \mathrm{PC}}\right)$ marks the growth rate of the long-term component of the supply of real balances corrected for longterm changes in money demand based on a standard demand function. There is obviously some resemblance between $\left(1_{2 \mathrm{PC}}\right)$ and $\left(1_{\mathrm{P} *}\right)$, but the precise formulation of the role of money is quite different. ${ }^{39}$

While most of the recent literature is agnostic about the theoretical underpinnings of the twopillar Phillips curve, others have made attempts to reason for it from a theoretical perspective. One possibility is to start from a standard forward-looking Phillips curve and simply to assume that money growth determines inflation expectations as in Gerlach (2004). ${ }^{40}$ Another would be to follow Neumann and Greiber (2004), who argue that if the behavior of actual inflation was linked to longer-run (or core) inflation, and core inflation was driven by the longer-run component of money growth by way of the quantity theory and a standard money demand function, $\left(1_{2 \mathrm{PC}}\right)$ might be a valid causal model of inflation.

The concept enjoys some support among monetary policy practitioners (AssenmacherWesche and others 2007) and is reported as describing euro-area inflation well (e.g.,

\footnotetext{
${ }^{38}$ See Benati (2005), Gerlach (2003), Jaeger (2003), Neumann (2003), Christiano and Fitzgerald (2003), Backhus and Kehoe (1992), or Lucas (1980) for other (also mostly empirical) work in the same direction.

${ }^{39}$ The difference to the P* model is less pronounced in Gerlach and Svensson's (2003) specification of the twopillar Phillips curve which is based on the real money gap instead of long-run excess money growth.

${ }^{40}$ See Bordes and Clerc (2007) for a similar discussion of the underpinnings of equation $\left(1_{2 \mathrm{PC}}\right)$. Interestingly, according to Gerlach (2004), the ECB (2001) in an early description of its policy framework explicitly allowed for the possibility of a direct impact of money on inflation expectations - a statement that was removed from later editions of the book (ECB 2004).
} 
Assenmacher-Wesche and Gerlach 2006a, 2006b)_-but the approach is not without drawbacks. As Nelson (2007) writes, in this model class identification of a link between money growth and inflation requires multi-decade averages of data. And, in a related comment, the OECD (2007) points out that this type of results is not always robust to changes in the sample period. For instance, excluding the 1970s period, a time of large common swings of money and inflation before what is now called the great moderation, tends to weaken the link between money and inflation.

However, the most severe criticism of the model has come from the theoretical side. As already highlighted in Section III.A, the standard NKM approach with added money demand can be shown to produce long-run empirical implications that are observationally equivalent with the empirical facts captured by the two-pillar Phillips curve while rejecting causality of money for inflation across both in short- and long-run (Woodford 2008). ${ }^{41}$ Therefore Nelson (2003) concludes that models such as of the two-pillar Phillips curve variety provide no valid test for evaluating a possible causal role of money for inflation. And Woodford (2007) points out that, once a structural general equilibrium model such as the NKM is available to account for the relation between money and inflation across all time horizons, there is little need for a partial modeling effort to capture the longer-run inflation dynamics separately. By extension, this argument also holds for generalized versions of the New Keynesian DSGE model thatother than the standard model favored by Woodford (2007, 2008) - allow money a causal role in the determination of money.

This discussion suggests that, not unlike the $\mathrm{P}^{*}$ approach, the two-pillar curve does not add significantly to the arguments for a more prominent role of money in Section III.B.

\section{Summary}

The theoretical debate suggests that there are a number of advantages to the general equilibrium approach. One obvious point is that the DSGE framework allows a fuller view of the role of money can play in the economy than any partial equilibrium model, including by capturing equilibrium feedbacks and by allowing for model-consistent forward-looking expectations. DSGE models are also less prone to the Lucas critique.

What is even more important, however, is that taking advantage of DSGE modeling does not mean ignoring the potential role of money in the economy. On the contrary, as Papademos (2006, p. 6) rightly points out, DSGE models have "...the potential to incorporate in a substantive way the role and effects of money and credit in the monetary transmission mechanism." While supporters of a strong role of money in monetary policy might have been temped to look at partial equilibrium models for support in the past, the advent of generalized versions of the "cashless" New Keynesian baseline model makes this less of a necessity. These models allow for a causal as well as an informative role for money in the economy and, thus, seem to capture well most arguments made within the confinements of the partial

\footnotetext{
${ }^{41}$ Compare Nelson (2007) and Beck and Wieland (2007b), who discuss the two-pillar Phillips curve but ultimately reject it as atheoretical. Ireland (2004), too, states that a thorough analysis of the role of real balances in the macro economy may require more than adding money to the Phillips curve.
} 
equilibrium approach. This holds for the short- as well as the long-run, where it has been convincingly argued that the implications of the DSGE are well in line with the empirical predictions of the quantity theory. Also, much like many pragmatically minded partial equilibrium models, modern DSGE approaches have been amended to better describe the data, for instance through the introduction of habit persistence arguments or partial indexation to complement the purely forward-looking models.

In the light of these findings, a merger of the two pillars of the ECB's monetary strategy is recommendable. The ongoing discussion of the relevance of money in the macro economy suggests that an exclusive focus on non-monetary (or "economic", in ECB parlance) factors alone may leave euro-area policy makers with an incomplete picture of the economy. And treating monetary factors as a separate matter, using potentially inferior partial-equilibrium tools to cross-check the implications of the "economic pillar", is obviously a second-best solution to this problem. Indeed, the natural approach seems to be a merger of the two analytical "pillars" of the ECB's monetary strategy within a general-equilibrium inspired analytical framework incorporating both monetary and non-monetary determinants of inflation. Of course, just as the current "monetary pillar" is not explicitly linked to a particular partial equilibrium model, the merged framework will not be reduced to a particular model, rather than to the general idea or narrative.

Of course, even a focus on general equilibrium models does not necessarily guarantee a clear-cut answer to the question about the weight to be attached to monetary analysis in such a unified analytical setup. In fact, it seems difficult (if not impossible), to come to a final view on theoretical grounds alone (see Table 1). One the one hand, not all generalequilibrium arguments in favor of a prominent role of money are considered quantitatively important in the literature. This holds, for instance, for the non-separability and credit channel effects within the New Keynesian approach. And while there is something to be said for the idea that monetary indicators can provide helpful forward-looking information for policy makers, the discussion of its economic relevance has just begun. On the other hand, money may matter through the sum of all these factors, leaving the option for a relevant role of money overall.

Against this background, there is an increased interest in assessing the validity of these arguments empirically. Section IV will take a closer look at the existing literature and present some new results. 
Table 1: Arguments in Favor of a More Prominent Role for Money: Overview

\begin{tabular}{lll}
\hline \hline Argument & Mechanism & Monetary variable to watch \\
\hline Causal & $\begin{array}{l}\text { Non-separable utility function: money influences } \\
\text { consumption decisions and price setting }\end{array}$ & $\begin{array}{l}\text { Real money, deviation from steady } \\
\text { state }\end{array}$ \\
Causal & $\begin{array}{l}\text { Financial frictions: bank lending influenced by } \\
\text { money supply, impacts investment decisions }\end{array}$ & $\begin{array}{l}\text { Real money, deviation from steady } \\
\text { state }\end{array}$ \\
Determinacy & $\begin{array}{l}\text { Multiple equilibria: policy strategy focused on money } \\
\text { prevents volatility from equilibrium indeterminacy }\end{array}$ & $\begin{array}{l}\text { Real money, deviation from steady } \\
\text { state }\end{array}$ \\
Information & $\begin{array}{l}\text { Adjustment costs: Smoothing of balances conditions } \\
\text { money on future output and interest rate path }\end{array}$ & $\begin{array}{l}\text { Real money, deviation from steady } \\
\text { state }\end{array}$ \\
Information & $\begin{array}{l}\text { Long-run correlations / Cross-Checking: Long-run } \\
\text { money growth indicates potential output growth }\end{array}$ & $\begin{array}{l}\text { Real long-run money growth, excess } \\
\text { over observed long-run output } \\
\text { growth }\end{array}$ \\
& &
\end{tabular}

\section{Partial Equilibrium}

\begin{tabular}{lll} 
Causal & $P^{*}$ model: price level ultimately determined by \\
money stock & $\begin{array}{l}\text { Real money, excess over } \\
\text { equilibrium demand }\end{array}$ \\
Causal & $\begin{array}{l}\text { Long-run correlations / Two-pillar Phillips curve: } \\
\text { inflation reacts (also) to long-run money growth }\end{array}$ & $\begin{array}{l}\text { Real long-run money growth, excess } \\
\text { over long-run demand growth }\end{array}$ \\
\hline
\end{tabular}

\section{THE IMPORTANCE OF MONEY FOR INFLATION FORECASTS}

There are several reasons why an empirical perspective might be informative with regard to the role of money in monetary policy. First, the theoretical debate is hardly conclusive. In fact, while there are indications that money has at least some causal influence on inflation or might, in addition, provide information about its future time path, the economic relevance of these channels remains mostly an empirical question. Second, there could also be a purely empirical argument in favor of a prominent role for money in monetary policy. A forward-looking policy maker may take the pragmatic position that money deserves attention if it proves helpful in forecasting inflation, no matter the precise channels through which this occurs. Thus, both on theoretical and empirical grounds, a monetary strategy placing special weight on money would seem particularly convincing, if money proved exceptionally helpful in forecasting inflation.

However, the picture emerging from the empirical literature so far is fairly mixed. On the one hand, a number of studies conclude that money provides relevant information about euro-area inflation; on the other, results for the U.S. and cross-country studies often point in the opposite direction. What is more, there is a discussion on the economic relevance of monetary in comparison to other factors. In light of this, in what follows we will briefly review the existing literature, including recent IMF research on this topic.

\section{A. A Brief Survey of the Empirical Literature}

A number of studies suggest that the indicator properties of money for inflation may be limited - either because money-based models do not perform well in a cross-country 
framework or because money is severely outperformed by other indicators. For example, Roffia and Zaghini (2007) show that, over a three-year horizon, in a panel of 15 industrialized countries starting in early 1970s, episodes of strong money growth are related to higher inflation only in about half of the 71 cases. De Grauwe and Polan (2005), looking at a large panel of about 160 countries since the 1970s find that the relationship between money and longer-run inflation is weak at best for low-inflation regions comparable to today's euro area. Gerlach and Svensson (2003, p.1669) find that the growth rate of nominal M3 adds little to the forecasting accuracy of an output-gap based model of euro-area inflation, which to them suggests "considerable doubt on its usefulness for policy purposes." Similarly, Stavrev (2006) finds that inflation forecasts for the euro area based on some quantity-theory inspired inflation models are outperformed by non-monetary approaches. And, finally, the OECD (2007) reports results from an euro-area inflation forecasting "horse race" between alternative time-series models suggesting that money played a prominent role only up to 2000. After 2000, for instance, real time measure of the output gap out-performed money as a predictor of inflation (OECD 2007).

In contrast, another strand in the literature suggests that partial equilibrium models can help forecasting euro-area inflation. Among others, the Bundesbank (2005) reports that $\mathrm{P} *$ models akin to the ones discussed in Section III.C are linked to euro-area inflation trends. Fischer and others (2008) report that the ECB has internally used $\mathrm{P}^{*}$ models to forecast inflation. Gerlach (2004) and Assenmacher-Wesche and Gerlach (2006a, 2006b) all show a significant contribution of longer-run movements in money growth (appropriately filtered) in two-pillar Phillips-curve type dynamic inflation equations along the lines of equation (12PC) in

Section III.C. And, according to Gerlach and Svensson (2003), a real money gap representation of the $\mathrm{P}^{*}$ model along the lines of equation $\left(1_{\mathrm{P}^{*}}\right)$ adds to the predictive power of a conventional Phillips curve approach.

Other studies imply that trend M3 growth is a predictor of inflation over medium-term horizons. For example, Following Nicoletti-Altimari (2001), Hofmann (2008) finds that trend growth of M3 is, as a rule, useful for inflation forecasts at medium-term horizons, although its forecasting performance has declined recently. Scharnagl and Schumacher (2007) use a Bayesian estimation framework to identify single monetary and real variables as well as groups of such variables that significantly predict euro-area inflation. The results suggest that a measure of trend M3 growth is the only monetary variable with relevant and time-invariant predictive power on its own, and that monetary variables as a group work well in forecasting models that also feature some real variables.

Finally, in a recent contribution, Berger and Österholm (2008a) show that, while M2 as well as M3 growth can help improve forecasting models of euro-area inflation in a mean-adjusted Bayesian VAR framework, the size of this improvement tends to be very small. Using a model based on data from 1970 to 2006 and forecasting horizons of up to twelve quarters, they find surprisingly strong evidence that adding money to both univariate and trivariate models (including, in addition to inflation, real GDP growth and interest rates) improves forecasting accuracy. The results are very robust with regard to alternative treatments of priors and sample periods. However, the predictive marginal power of money growth for inflation is substantially lower in more recent sample periods compared to the 1970s and 1980s. Interestingly, the result seems not to be an artifact of the particularities of the euro 
area: a related paper reports similar findings for M2 growth in the U.S. (Berger and Österholm 2008b).

\section{B. A Systematic Analysis of the Information Content of Money}

A number of things may explain these widely differing results, with important implications for any systematic approach to evaluating the information content of money in forecasting inflation. One factor is sample selection. D'Agostino and others (2006) make the point that the predictability of macroeconomic variables in general may have been lowered as macroeconomic volatility declined during the great moderation. ${ }^{42}$ In a related result, de Grauwe and Polan (2005) report that the relationship between money and longer-run inflation is the strongest in high-inflation countries. This suggests focusing any comparative analysis of competing models of inflation on a unified sample period, preferably a recent one to maximize the relevance of results for policy makers.

Another factor will be differences in the empirical approach, The literature has employed a wide variety of inflation models, both empirical and structural, ranging from simple time-series models to sophisticated general dynamic factor model (GDFM) approaches and more structural, theory-guided setups. ${ }^{43}$ While all these models incorporate money one way or the other and can, in principle, be compared with non-monetary approaches, their comparison would be more straightforward in a nested framework. In particular, the marginal contribution of money to inflation forecasting accuracy should be evaluated for a particular model class, comparing the forecasting performance of a model that encompasses monetary variables with a related one that does not. ${ }^{44}$ Such an exercise is akin to a Granger causality test in a multivariate environment (Ashley and others 1980, Berger and Österholm 2008a).

Finally, it would be helpful to employ structural models in addition to the idea of Granger causality testing. As among others Woodford (2008) and Galí and others (2004) warn, empirical correlation does not necessarily imply theoretical causality. In particular, the identification of an empirical link between money and inflation may not be sufficient to give money a special role in the determination of inflation. After all, both variables may be simultaneously determined by an omitted driving variable, as the New Keynesian DSGE model would suggest (see Section III.A).

Following these arguments, Berger and Stavrev (2008) provide a systematic analysis of the information content of money for inflation in the euro area. They compare the simulated out-of-sample forecasting performance of models with and without money for the period

\footnotetext{
${ }^{42}$ They work with U.S. data, but the point is general in nature.

${ }^{43}$ Yet another strand of research, as e.g. in Stavrev (2006) and Hofmann (2008), combines a variety of approaches for inflation forecasting. While perhaps helpful as a forecasting tool, this approach provides little guidance for the question at hand.

${ }^{44}$ This seems also to be what the OECD (2007) has in mind when it suggest that, given the multitude of approaches, "in coming to an overall assessment it is best to look at results from a wide variety of statistical approaches and try to make a judgement based on the relative strengths and weaknesses of each technique."
} 
2000-2007 for a number of typical model classes in the literature using Bayesian estimation techniques where appropriate. ${ }^{45}$ The model classes include, on the empirical side, pure time series and GDFM approaches and, on the structural side, both partial and dynamic general equilibrium models that are conceptually equivalent to the ones discussed in Section III. The within-class comparison is based on the out-of-sample root mean square errors (RMSEs) at forecasting horizons of one, four, eight, and twelve quarters ahead. A lower RMSE implies better forecasting accuracy at a particular horizon. Figure 3 summarizes key results from their paper.

An important first finding is that among the structural New Keynesian DSGE models the money-enhanced generalized approaches perform well compared to the cashless NKM baseline (Figure 3, first row). ${ }^{46}$ The size of the improvement in forecasting accuracy from adding money is a matter of perspective. For instance, at a forecasting horizon of eight quarters, introducing non-separability reduces the RMSE compared to the cashless baseline without habit persistence by about 0.25 percentage points of inflation, while the improvement from adding adjustment costs is only about 0.1 (left Figure). At about 0.4 and 0.5 , the improvements from adding money to the baseline NKM with habit persistence at the same horizon (right Figure) are higher and seem to have a more relevant empirical dimension. On the other hand, viewed across all forecasting horizons, the average improvement in RMSE is no higher than 0.3 percentage points for either group of models in the NKM class. ${ }^{47}$

\footnotetext{
${ }^{45}$ All models are initially estimated over the same training period, 1993Q1 to 1999Q4, and their inflation forecasting performance is assessed for the period 2000Q1 to 2007Q2. See Berger and Stavrev (2008).

${ }^{46}$ The adjustment cost results are particularly interesting because Berger and Stavrev (2008) condition the central bank's interest rate function on model-consistent expected inflation. The improvement in forecasting accuracy from incorporating monetary factors in the interest rate rule suggests that money supplies additional information. As discussed in Section III.B, one reason could be that because of informational frictions the central bank does not fully observe the state of the economy reflected, in part, in monetary developments.

${ }^{47}$ Money affects inflation mainly through improving the empirical specification of the aggregate demand and aggregate supply equations, while the effects from the fact that monetary policy reacts to money balances in the generalized models (see Section III.B) is small.
} 
Figure 3. Forecast Performance of Various Inflation Models

(RMSE of dynamic forecasts, in percentage points of year-on-year inflation)
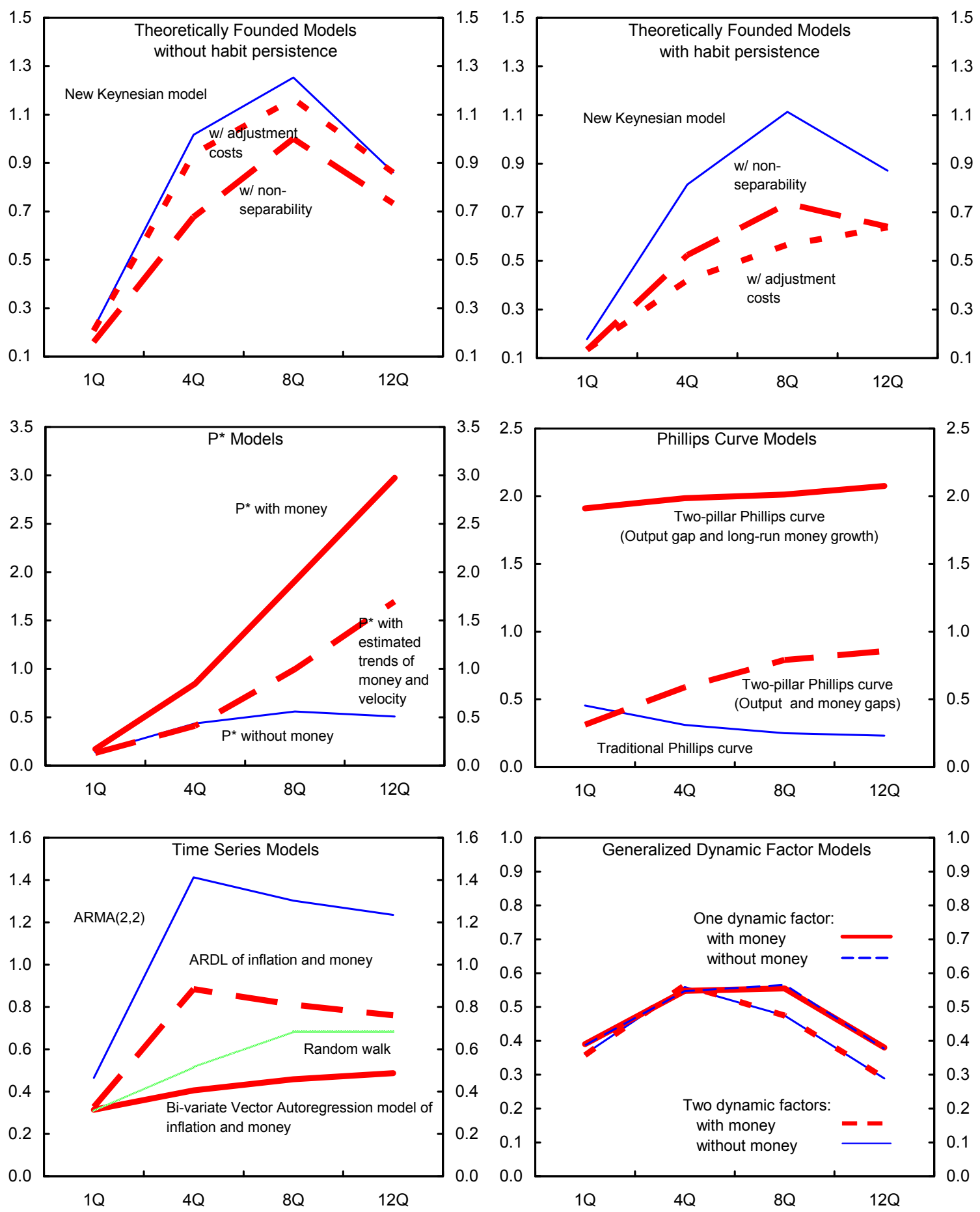

Sources: Berger and Stavrev (2008). 
In addition, they find that money does improve inflation forecasting performance of some time-series models (Figure 3, third row, left panel). An autoregressive distributed lag (ARDL) single equation approach containing money, while not beating the simple random walk model, delivers better inflation forecasts than the ARMA approach. The best time-series model in terms of RMSEs across all horizons is a bivariate BVAR model. At about 0.5 to 1.0 percentage points on average, the reduction in RMSE gained by the bivariate VAR model against the ARMA is considerable, but the improvement against the random walk model is modest at best. These results are consistent with other studies in the literature that have used time-series models (e.g., Berger and Österholm 2008a, Fischer and others 2008). On the other hand, Berger and Stavrev (2008) also report that incorporating monetary indicators in the GDFM models does little to improve inflation forecasting performance once a broader set of economic indicators is taken into account (Figure 3, third row, right panel). The two-factor GDFM model with money does better in forecasting inflation than the two-factor model without money, but the reduction in RMSEs is miniscule. The reverse holds for the one-factor GDFM model. These results seems to run against Hofmann (2008), who reports that factor models with money do consistently better than factor models without money in forecasting inflation over the twelve-quarter horizon.

Turning to partial equilibrium models, the results in Berger and Stavrev (2008) imply little or no role for money (Figure 3, second row). More specifically, the simplest $\mathrm{P}^{*}$ model without money (where the price gap is the deviation of the price from an estimated equilibrium level) has the best forecast performance in this class of models, with the two models incorporating money (including the money-gap P* approach in Section III.C) lagging far behind (left panel). Similarly, among the reduced-form Phillips curve models, the standard formulation excluding money produces the best forecast among this group of models at longer horizons, with the two-pillar Phillips curves, and, in particular, the one with long-term money growth along the lines of Section III.C, faring much worse.

An interesting observation comparing the performance of the money based approaches across the various model classes is the seemingly "u-shaped" relationship between the degree of their theoretical underpinnings and their forecasting performance: the best empirical model and the best DSGE model do better than best partial equilibrium model. A corollary of this is that, from a forecasting standpoint, it is clear that the information content of money is not necessarily adequately captured by money growth (or its long-term component) alone, or even by adding a thorough specification of trend values, as in the two $\mathrm{P}^{*}$ models with money - instead, a more explicit modeling of the dynamics and underlying theoretical structure of the money-inflation relationship seem to be called for. ${ }^{48}$

Berger and Stavrev (2008) conclude that the quantitative importance of money for inflation forecasting is rather limited. The improvement in RMSE from adding money in a particular

\footnotetext{
${ }^{48}$ One possible explanation for the relatively weak performance of the money-enhanced partial equilibrium may be their particular sensitivity to money demand instability. Fischer and others (2008) also note that, from the perspective of forecasting practitioners, simple bivariate models foregoing an explicit money demand specification are dominating other approaches.
} 
model class is often very small. In addition, in a horserace of all forecasting models - while not at the core of the empirical exercise geared toward within-model class comparison-the best performers are money-less models. Even though the quantitative advantage of the moneyless models is not always large, these findings, too, put the role of money in an integrated empirical setting into perspective.

\section{Summary}

Not unlike the theoretical literature, the empirical debate on the role of money in monetary policy is ongoing. Much of the empirical literature focuses on the usefulness of money in inflation forecasting, a task that arguably is also of high interest for practitioners of monetary policy. The results overall seem to be mixed, with some papers declining that money plays a useful role in enhancing forecasting accuracy of inflation in the euro area and elsewhere, while others tend to support such a role.

A systematic comparison of these studies is often difficult. One complication is that sample periods and empirical approaches vary widely. Another issue is that there is little discussion of causality. For instance, rather than focusing on the marginal contribution of money within a certain model class, comparative studies such as Nicoletti-Altimari (2001), OECD (2007), or Hofman (2008) tend to focus more on overall horse races across model types. And little work has been done so far using structural general equilibrium approaches, which allow perhaps the most direct test for a causal role of money with regard to modeling present and future inflation.

Moving in this direction, recent IMF staff research suggests that money may indeed contribute to forecasting accuracy within a number of model classes. Evaluating the relative out-of-sample inflation forecasting performance of models with and without money for a uniform sample period, the results show, for instance, that money-enhanced structural New Keynesian DSGE models outperform their cashless counterpart, signaling both a causal and an informative role for money. A positive marginal contribution of money to forecasting accuracy is also found for some of the purely empirical models. However, partial equilibrium models with money often perform worse than their money-less counterparts. In addition, there is an interesting "u-shaped" relationship between the degree of the theoretical underpinnings of the inflation models and their forecasting performance: the best non-structural empirical model and the best DSGE model are doing better than the best quantity-theory inspired partial equilibrium models.

This research also shows, however, that the quantitative contribution of money to inflation forecasting accuracy is often small. Depending on the model class, the marginal improvement in terms of the RMSE of the forecasting error can be miniscule. What is more, in an all-out the horserace money-enhanced models tend to be dominated by non-monetary models. While not at the core of the empirical exercise (which is geared toward within-model class comparison) and even though the quantitative advantage of the moneyless models is not always large, this also warns against overestimating the role of money in an integrated empirical setting. 


\section{Disaggregated Monetary Analysis}

Since the inception of the ECB, the evolution of M3 has posed a challenge for the ECB's monetary analysis. M3 growth has continuously exceeded its reference value of $4 \frac{1}{2}$ percent since June 2001, often by a wide margin, but inflation has hovered around 2 percent, close to the ECB's definition of price stability. The apparent decoupling of money growth and inflation occurred against a background of surging financial innovation, deregulation, as well as increasing use of internet banking, which lowered financial transaction costs significantly. At the same time, many financial assets, including money market funds and equities, turned into close substitutes to money, as measured by M3, and, as a consequence, the impact of shifts in domestic or internationally diversified asset portfolios on M3 has increased.

Although the precise repercussions and links between these developments and M3 growth are subject to some debate, it seems likely that they have contributed to distorting the relation between money growth and inflation.

Figure 4. Euro Area Money Growth and Inflation

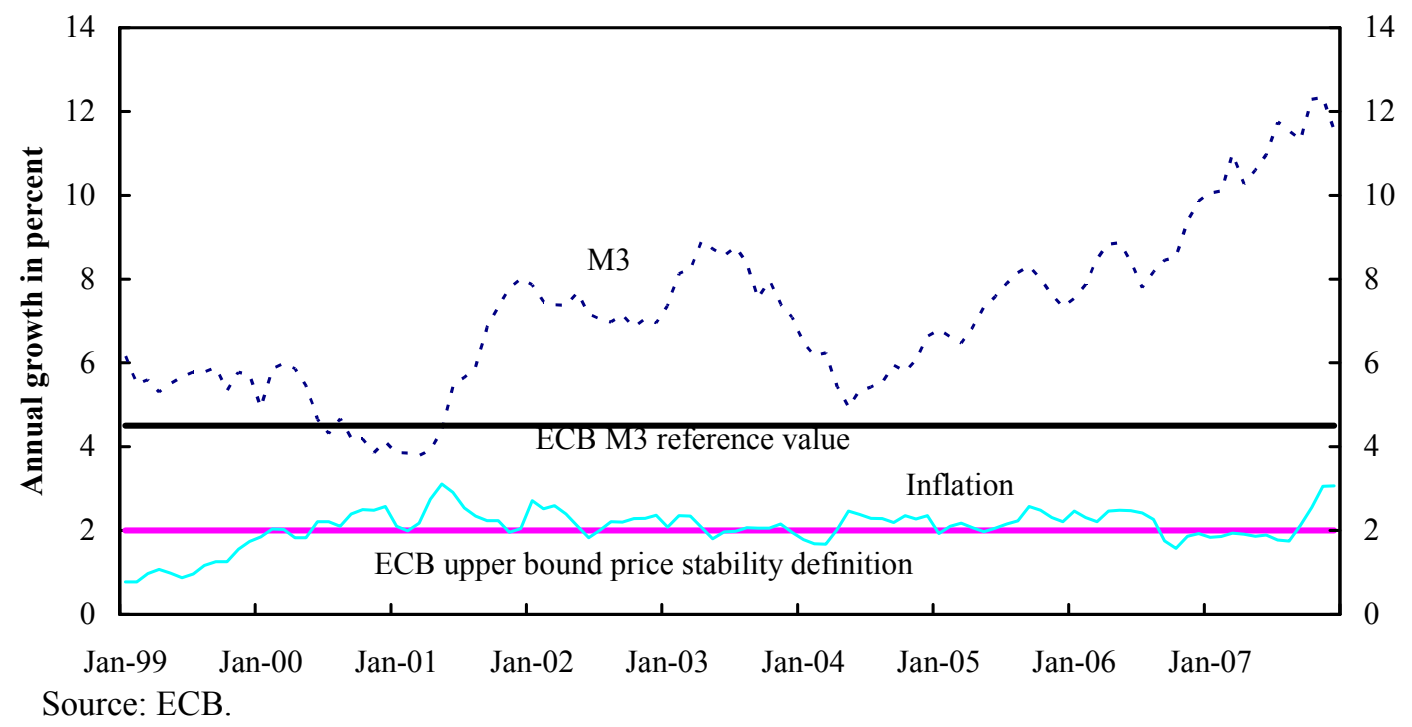

Partly in reaction to these developments, in 2003 the ECB adjusted its monetary strategy framework, broadening its monetary analysis to explicitly account for changes in the institutional features of the monetary and financial sector (see Section II). Disaggregated monetary analysis, including the close monitoring of M3 components, is seen as a natural starting point for the assessment whether M3 variations are broad based and a useful indicator of future price trends, or may need to be adjusted - for instance because they reflect preference shocks to financial portfolios including elements of M3.

This section will provide a brief discussion of ECB's monetary analysis framework focusing on its disaggregate aspect. In particular, it will discuss the ECB's judgmental analysis and adjustments to $\mathrm{M} 3$ in response to financial innovation and integration, including international portfolio shifts and securitization. 


\section{A. The Background of the ECB's Disaggregate Monetary Analysis}

The ECB has repeatedly pointed to the observation that money and inflation are closely related over the medium- to long-run horizon in the euro area, with money leading inflation by as much as three years. Implicit in its assessment of the particular importance of money for medium- to long-term price trends is the presumption that money affects inflation and not vice versa. While a structural or causal relationship between money and inflation can be modeled in a number of ways (see Section III), the economic concept most closely related to the ECB's reference value approach is certainly the quantity theory of money.

Consider the quantity identity

$$
m_{t}+v_{t} \equiv p_{t}+y_{t}
$$

where $p_{t}$ denotes the price level, $m_{t}$ the nominal stock of money, $y_{t}$ real output (all in logs) and $v_{t}$ is the $(\log )$ income velocity of money at period $t$. After rearranging this equation, real balances or real money demand equal real output corrected for velocity

$$
m_{t}-p_{t}=y_{t}-v_{t} \text {. }
$$

If prices were fully flexible, velocity constant and the available nominal money supply modeled as an exogenous (policy) variable, any change in the nominal stock of money would result in a proportional change in prices and (real) money demand would, again, equal the supply of real money balances. With these assumptions the quantity identity becomes a simple quantity theory of the price level that implies that any change in the nominal stock of money or its growth rate will — at least over the longer run - result in a proportional change in prices or inflation and, in that sense, inflation would mainly be a monetary phenomenon.

But there are two important objections or caveats to the hypothesis that there should be a stable and causal relationship from money to prices. First, velocity is not constant, and, second, money is not fully exogenous. We will discuss these issues in turn.

\section{Velocity is not constant}

In most empirical studies, velocity is characterized by large swings or trends over time while also exhibiting high short-run volatility. To illustrate, Figure 5 shows income velocity of various monetary aggregates in the euro area (left panel) and the G7 (right). These empirical features are at odds with the idea of a constant velocity underlying a simple and stable relationship between money and prices. Any objection to the existence of such relationship on the basis of variable velocity could be rectified, however, if there were nevertheless a stable functional demand for real money that in turn would imply a systematic and stable relationship between velocity and other endogenous variables, including the interest rate. 
Figure 5. Income Velocity in the Euro Area and Other G-7 Countries
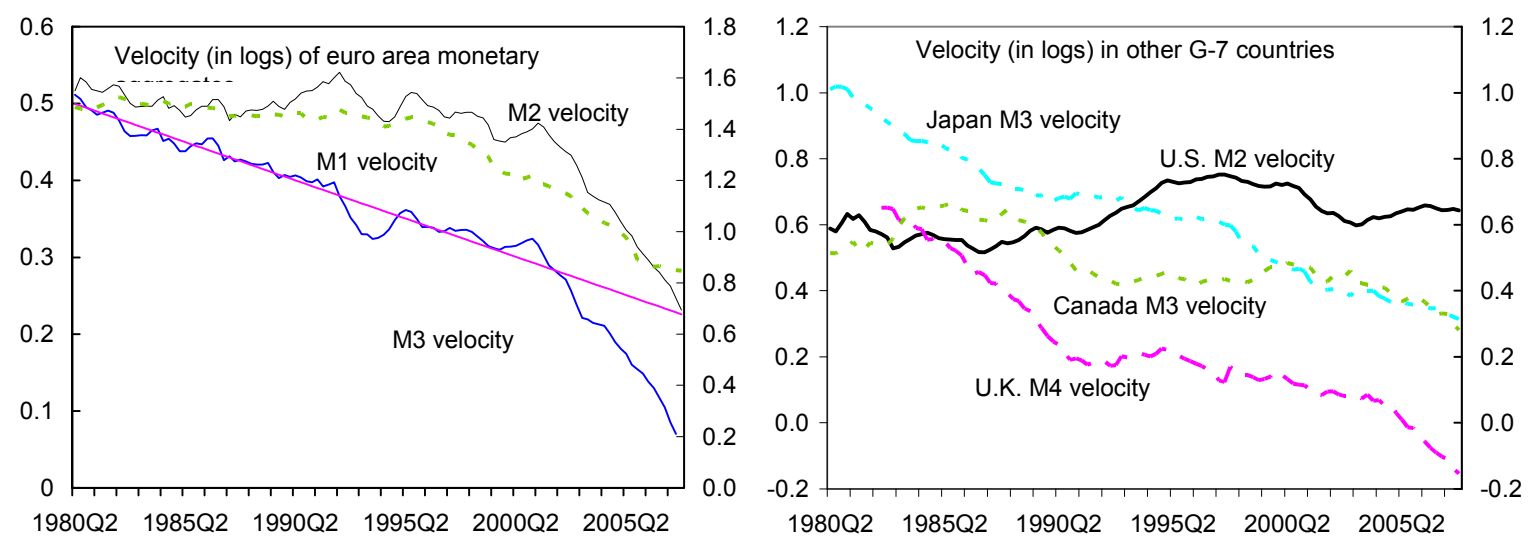

Sources: ECB and IMF.

Notes: Velocity is defined as $v_{t}=p_{t}+y_{t}-m_{t}$ along the lines of equation (1). The left-hand panel also shows a linear trend for M3-based velocity over the full sample period.

Money demand and, thus, velocity, can take various forms. A straightforward cash-in-advance constraint implies constant velocity and, accordingly, interest inelastic demand for money. Simple opportunity cost considerations imply interest elastic money demand and variable velocity. But money demand may also be determined in a complex portfolio calculation where households trade off the expected returns and risks of a multitude of assets, taking account the transaction costs of portfolio adjustments.

For example,

$$
v_{t}=f\left(i_{t}, s_{t}^{1}, s_{t}^{2}, s_{t}^{j} \ldots, s_{t}^{n} ; \sigma_{t}^{1}, \sigma_{t}^{2}, \sigma_{t}^{j} \ldots, \sigma_{t}^{n} ; t_{t}^{1}, t_{t}^{2}, t_{t}^{j}, \ldots, t_{t}^{n}\right),
$$

where $i_{t}$ denotes the nominal interest rate of a risk-free one-period bond, $s_{t}^{j}$ denotes the spread between $i_{t}$ and the return of some other asset $j, \sigma_{t}^{j}$ the risk associated with that return and $t_{t}^{j}$ the transaction costs associated with selling asset $j$. In such a model, any change in spreads, risks or in the perception of risks and in transaction costs may induce portfolio shifts that affect velocity and the real demand for money and, accordingly, blur any simple one-to-one link between the nominal stock of money and prices. And the variability in velocity and real money demand would be the higher the lower the level of transaction costs and, therefore, the higher the degree of substitutability between money and other assets.

Conceptually, a broadly defined money demand function based on a sufficiently general concept of velocity as in (3) may well be able to account for and predict velocity shifts while preserving the link between money and prices. However, financial innovation, technological progress and financial integration or deregulation are prone to change the functional form of $f($.) in (3) or change the set of relevant assets $n$ in an unpredictable and erratic manner. Since the 1970s, when cash and demand deposits were the predominant means of most economic transactions, there has been a host of financial innovations including credit cards, electronic money, money market accounts and internet banking. Transaction costs of trading most financial assets fell rapidly and many became close substitutes to cash and overnight 
deposits. These developments, by nature hard to predict, have seriously undermined the concept of stable velocity or real money demand. Friedman and Kuttner (1996) argue that the problem of instability is especially severe in a modern financial system that offers any number of assets, of which only an arbitrary subset will be included in a given definition of a monetary aggregate.

There is still a lively empirical debate on the stability of conventional money demand functions in the euro area, with some studies finding money demand functions in the euro area to be, while not without problems, more stable than in other regions, in particular the U.S. ${ }^{49}$ A number of factors might explain this finding. First, financial deregulation in the euro area was less rapid than in the U.S. Second, due to differences in the financial system, the type of financial innovation may have been different. Third, monetary euro area data prior to 1999 are a composite of national data and averaging helps stabilizing euro area money demand through potentially offsetting national demand shocks and the implicit inclusion of foreign aggregate explanatory variables. Finally, the well-known historical stability of German money demand comes to bear in euro area-wide estimates of money demand models.

Others maintain that the stability of euro-area money demand requires taking into account the influence of asset markets, reflecting the spirit of equation (3). For example, Greiber and Lemke (2005) show that stable money demand functions can be estimated if measures of uncertainty are included in the model, which help to explain what are considered portfolio or preference shifts in liquidity demand. Fererro and others (2007) also argue that there is evidence that the recently observed increase of euro-area M3 growth may be due to portfolio choices and the acceleration of non-bank financial intermediaries' money demand. And, in related work, Greiber and Setzer (2007) show that housing prices systematically influence money demand both in the US and the euro area. One explanation could be a higher transaction volume through wealth effects on consumption or increasing construction activity. They argue that this relationship can help explain signs of instability in standard money demand function. Along similar lines Boone and others (2004) include proxies for wealth (house and stock prices) to allow empirical money demand function to capture the post-2000 euro area money surge.

But there are a number of indications that despite these efforts, a stable money demand will prove elusive even in the euro area. For instance, Faruqee (2005) and Bordes and others (2007, pp. 2-5) identify structural breaks in the log velocity of money even after correcting for portfolio shifts and the influence interest rates, ultimately rejecting the "existence of a strong, stable, and predictable relation between money and prices in the euro area", which "may call for some adjustments in the conduct of the ECB's monetary policy." Along similar lines, Fischer and others (2008, p.111) also stress that, while the ECB has found

\footnotetext{
${ }^{49}$ For instance, Bruggeman and others (2003) find long-run euro area money demand consistently related to real GDP. Dreger and Wolters (2006) also argue that standard money demand functions are well capable of explaining the recent surge in euro area liquidity provided that the short-run homogeneity restriction on money and prices is dropped. See, among others, the surveys by Calza and Sousa (2003), Golinelli and Pastorello (2002), and Ericsson (1998).
} 
portfolio-enhanced money demand functions helpful in explaining M3 behavior during certain periods, these models tend to produce "anomalies" during other times.

Most importantly, however, there is reason to suspect that the relative stability of euro area compared to U.S. money demand functions will eventually disappear once euro-area financial deregulation and integration has reached U.S. levels. Many countries in the euro area had relatively closed and heavily regulated financial markets during most of the 1970s and 1980s, and financial progress occurred at a much slower pace than in the U.S. With the introduction of a common currency, together with a sharp acceleration in financial deregulation and integration, however, it appears very likely that the recent instability of velocity and money demand in the euro area will persist or even increase over time. For the U.S., at least, there is broad consensus that financial innovation and technological progress contributed greatly to the instability of velocity and money demand. In response, the U.S. Federal Reserve significantly downgraded its monetary analysis in the early 1990 s. $^{50}$

\section{Money is not fully exogenous}

Another threat to a simple causal relationship between money and prices is the endogeneity of the nominal stock of money. When fiat money was first introduced and central banks defined the initial value of account, money was widely considered a (exogenous) policy instrument under the control of the monetary authorities. Nowadays, central banks are still controlling the issuance of legal currency and exert significant direct influence over some bank deposits, including overnight or demand deposits. But other components of money, such as the amount of money market funds and debt securities that are part of the ECB's concept of broad money M3 (see, Table 2) are largely determined by markets.

Table 2: Definitions of Euro Area Monetary Aggregates

\begin{tabular}{|c|c|c|c|}
\hline Liabilities $^{1 /}$ & M & $\mathbf{M}$ & M3 \\
\hline Currency in circulation & $\mathrm{X}$ & $\mathrm{X}$ & $\mathrm{X}$ \\
\hline Overnight deposits & $\mathrm{X}$ & $\mathrm{X}$ & $\mathrm{X}$ \\
\hline Deposits with an agreed maturity up to 2 years & & $\mathrm{X}$ & $\mathrm{X}$ \\
\hline Deposits redeemable at a period of notice up to 3 months & & $\mathrm{X}$ & $\mathrm{X}$ \\
\hline Repurchase agreements & & & $\mathrm{X}$ \\
\hline Money market fund (MMF) shares/units & & & $\mathrm{X}$ \\
\hline Debt securities up to 2 years & & & $\mathrm{X}$ \\
\hline
\end{tabular}

Source: ECB.

${ }^{1 /}$ Liabilities of the money-issuing sector and central government liabilities with a monetary character held by the money-holding sector.

The way the concept of money has evolved over time is closely related to the discussion of stable money demand above. The introduction of near perfect substitutes to currency and zero interest yielding demand deposits, which were considered the main components of

\footnotetext{
${ }^{50}$ See, for example, the discussion in Friedman and Kuttner (1996) and Kahn and Benolkin (2007).
} 
money in the past, has led to a broader definition of money that has been used for monetary analysis and specifications of money demand. Shifts between currency, zero interest yielding demand deposits and other forms of deposits largely reflect technical constraints, such as the amount of time involved in the clearing of checks and wiring balances, or finding and accessing an ATM for cash, instead of measurable variation in returns. ${ }^{51}$ As a consequence, many central banks, rather than augmenting money demand or velocity functions based on a narrow money concept such as M1, instead expanded the concept of money to M2, M3, or beyond.

But the ECB's choice of M3 as key monetary aggregate for gauging inflationary pressures is not beyond dispute. For example, Reynards (2007) argues that narrower money measures, such as M2 that are more closely related to the transactions demand for money, may be preferable. Also, the ECB's current broad money M3 concept includes most liabilities of the banking sector, while other, non-bank issued financial assets are becoming relatively close substitutes to M3 components. Any inclusion of these-moving from inside money to outside money that includes net assets of the private nonbank sector-would significantly alter further the concept and meaning of money.

As monetary aggregates such as the ECB's M2 or M3, considered relevant for gauging inflation pressures, are largely endogenous and outside the control of central banks, money targeting as the operational framework for monetary policy has been abandoned by most central banks. ${ }^{52}$ Instead, most monetary authorities set a policy target for the interest rate in the interbank overnight market and conduct their monetary operations, including repurchase agreements and outright asset purchases, to steer this rate close to the policy target, while even narrow money is determined endogenously. ${ }^{53}$ This move is supported by the advent of "cashless" New Keynesian general equilibrium models, where, with endogenous money and inflation, there is no clear direction of causality (Svensson 2003). Against this background, many have argued that a stable money demand or velocity function, if it existed, would not be very helpful in gauging inflationary pressures as movements in money would mainly reflect structural shocks to other variables, or financial innovations. ${ }^{54}$

\footnotetext{
${ }^{51}$ The demand for cash also depends on the size of an economy's informal sector and its use abroad.

${ }^{52}$ For instance, according to Friedman and Kuttner (1996), the Federal Reserve targeted money mainly during 1975-1982, in the sense that it varied either the federal funds rate or nonborrowed reserves (whichever, was the policy instrument at the time) in response to observed fluctuations or either M1 or M2 that departed from the corresponding stated targets.

${ }^{53}$ Some argue that money remains important for central banks to control the overnight interbank interest rate, but Woodford (2003) maintains that the achievement of the central bank's interest target does not require any quantity adjustments through open-market operations in response to deviations of the market rate from the target rate.

${ }^{54}$ See the discussion in Section III.A.
} 


\section{B. Judgmental Adjustments to M3}

In the ECB's view, the failure of standard money demand equations to systematically account for a significant part of variation in M3 in the euro area over the past decade has created a need for judgmental analysis and associated adjustments to M3. ${ }^{55}$ Its 2003 clarification of the "monetary pillar" (see Section II) emphasized that structural changes in financial markets and in the composition of wealth due to the increased sophistication of private investors may constitute a source of uncertainty regarding the definition of the monetary aggregate relevant for inflation. The ECB also highlighted that gaining a thorough understanding of the interdependencies between M3 and its counterparts in the consolidated balance sheet of the MFI sector was seen as instrumental in judging whether observed changes in money growth may, or may not bear implications for price trends later on. Accordingly, the ECB expanded its detailed component-based monetary analysis and offered further insight into some of the tools and frameworks used to conduct monetary analysis. ${ }^{56}$ Adjustments to M3 may reflect statistical, technical or economic changes or developments and rely on a detailed analysis of the monetary aggregates, their components and counterparts, as recorded in the consolidated balance sheet of the euro area monetary financial institutions (MFI) sector.

\section{M3 adjustments due to statistical and technical factors}

M3 adjustments due to statistical and technical factors mainly reflect changes in the monetary operations framework and improvements in measurement of the M3. For example, non-resident holdings of money market funds issued by euro-area MFIs were initially included in M3 because they are difficult to measure. M3 was subsequently revised to exclude these holdings after sufficiently reliable estimation methods for this component had been developed. The introduction of remunerated reserve requirements in several countries at the start of Stage III meant a technical adjustment to the monetary operations framework that may have led to repatriation of funds and temporarily elevated levels of M3 growth. While some of these adjustments may have temporarily complicated monetary analysis and its communication to the public, most were small and the transition to corrected measures of M3 was smooth.

\section{Portfolio shifts}

During 2001-03, there was a broad-based slowdown in economic growth in advanced economies. Sentiment was depressed further following the terrorist attacks that occurred in the U.S. in September 2001. In the U.S., economic output fell in early 2001 and subsequently in the euro area in 2003. At the same time, broad money growth accelerated markedly in the

\footnotetext{
${ }^{55}$ According to ECB staff, augmenting money demand equations after they have proven unstable over time should be seen as providing ex post support for the judgmental adjustment of M3 rather than a plausible alternative framework for making that judgmental assessment in real time (Fischer and others 2008).

${ }^{56}$ See, the ECB's Monetary Bulletins from October 2004 and July 2007.
} 
euro area and peaked at about 9 percent in May 2003. Interestingly, broad money growth in the U.S. decelerated sharply after reaching its peak in November 2001 (see Figure 6).

Figure 6. Annual Broad Money Growth in the U.S. and in the Euro Area

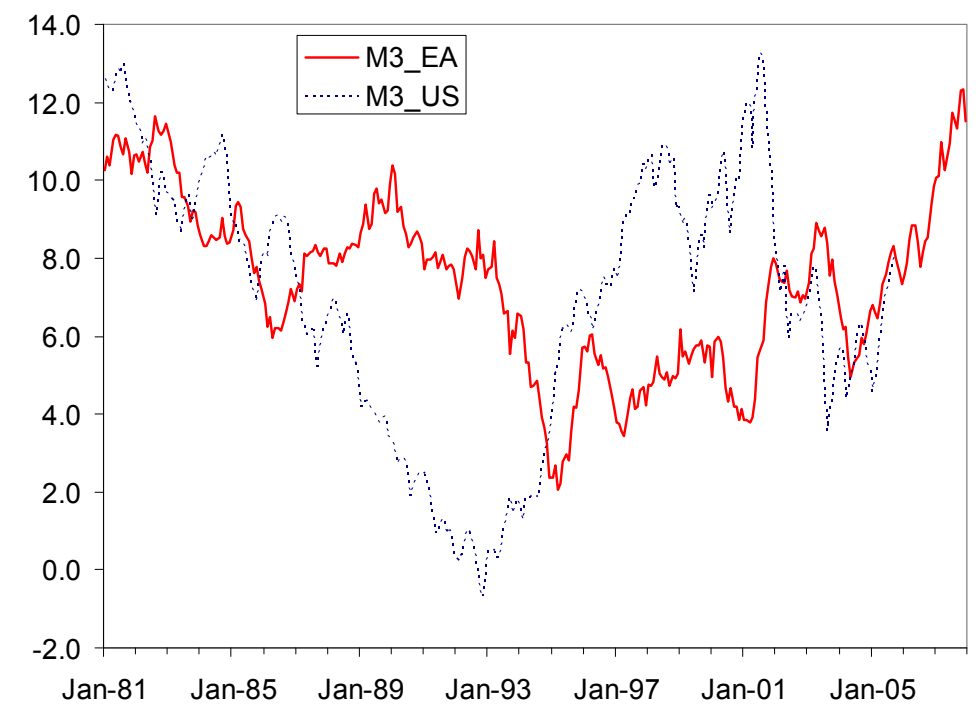

Source: IMF.

ECB staff provided several discussions of the elevated M3 growth rates observed during 2001-03, concluding that portfolio shifts reflecting euro area residents' strong demand for highly liquid domestic assets were mainly responsible for the temporary surge in M3 growth. ${ }^{57}$ According to the ECB (Monthly Bulletin January 2005, p. 13), the period of exceptional economic and financial uncertainty between 2001 and 2003 led to a strong preference by investors for liquid assets. The associated portfolio shifts were reflected in high M3 growth (Figure 7).

While this assessment appears perfectly reasonable, there are a number of competing explanations (Faruqee 2005) - and it remains unclear how to discriminate among them on the basis of a disaggregate monetary analysis alone. First, there is the question why M3 growth in the U.S., where much of the economic and financial uncertainty during this period had originated, sharply decelerated during 2002-03, following a surge that started in 1993 (Figure 6) . Second, the fact that the euro dollar exchange rate fell to its all time low during this period but has since appreciated strongly may indicate a link between U.S. liquidity and money and price developments in the euro area. ${ }^{58}$ Third, as Faruqee (2005) points out, the increasingly important international role of the euro could also have had implications for velocity and money demand. Finally, according to the ECB's own analysis, M3 dynamics

\footnotetext{
${ }^{57}$ See, for example, ECB Monthly Bulletins May 2003, October 2004, and January 2005.

${ }^{58}$ Berger and Harjes (2008) find a potential link between global liquidity, primarily determined by U.S. liquidity, and euro area inflation.
} 
during 2001-03 were associated in large part with transactions involving non-residents, thereby focusing attention on international financial flows. ${ }^{59}$ But if there had been a change in the home bias for financial assets, M3 developments should have been symmetric across advanced countries. Possibly, a change in exchange rate expectations may have played a role. In the end, a detailed discussion of banks' balance sheet items with little attention paid to prices, including exchange rates, or other variables may not be very helpful in adding structure to this analysis.

Figure 7: Annual M3 Growth, and M3 Velocity (in logs) and Its Trend, With and Without Portfolio Adjustment
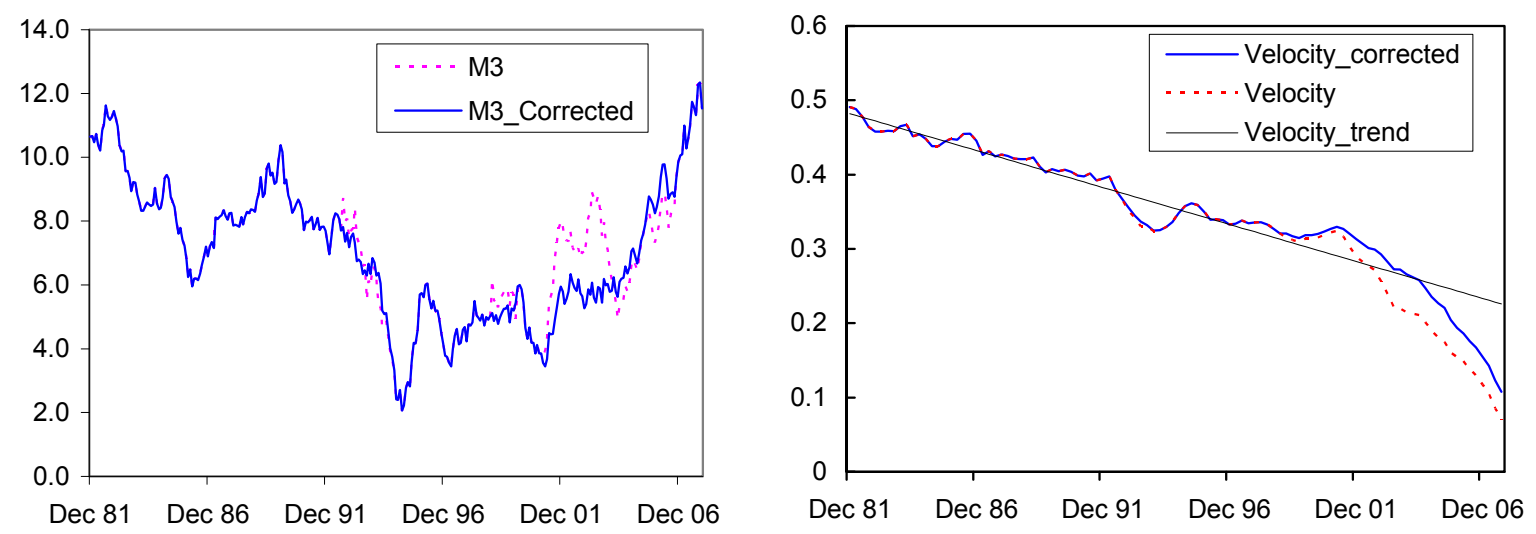

Sources: ECB, IMF calculations.

That portfolio-shifts were but one of the factors driving the post-2001 surge in M3 growth is also obvious from the limited impact of the ECB's judgmental adjustments on velocity. As Figure 7 reveals, M3 growth corrected by the ECB for portfolio shifts was lower during 2001-03 than unadjusted figures suggested and the adjustments smoothed the sharp deviation from the steady downward trend in velocity. Fischer and others (2008) and Pill and Rautanen (2006) have stressed the importance of these corrections, in particular during 2001-03, for improving the inflation forecasting properties of simple, single equation models that feature money and inflation. However, over the past years no further adjustments have been publicly discussed by the ECB, and eventually the corrected M3 growth and velocity have shown the same structural break as the uncorrected data. ${ }^{60}$ One implication is that the same single-equation models would now forecast a significant increase in inflation which is strongly at odds with the ECB's current (2008Q1) baseline prediction of annual average inflation to fall to about 2 percent in $2009 .{ }^{61}$

\footnotetext{
${ }^{59}$ See, ECB (2004b), p.49.

${ }^{60}$ See Faruqee (2005) for a more formal treatment of the question of structural breaks in euro area velocity.

${ }^{61}$ Staff calculations supporting these conclusions are available on request.
} 


\section{Securitization}

Another recent topic featuring with some prominence in the ECB's disaggregate analysis is securitization - but its overall impact on monetary analysis has been low so far. During 2004-2007, when M3 surged, securitization growth also accelerated dramatically (see Box 1). ${ }^{62}$ While it is not immediately clear as to why developments that primarily affect the composition of banks' assets should have any impact on money demand or income velocity of money, securitization may have contributed to increasing further the distortions of the empirically small signal from money to prices. The ECB $(2008$, p. 91) concludes that "the overall impact of loan securitization on money and credit aggregates is not easy to quantify.....Many different financing and investment transactions are presumably occurring simultaneously and may cancel each other out in terms of their impact on M3, but, if they take place at different points in time, they may lead to some short-term volatility in M3 developments." As a consequence, possible effects of securitization on M3 have not been captured in the ECB's corrected M3 series.

However, the discussion of securitization points to another possible function of a disaggregate perspective on monetary developments outside the realm of the core monetary strategy: disaggregate monetary analysis may provide useful input into the ECB's assessment of financial stability. The recent financial turmoil surrounding the so-called subprime crisis is predominantly reflecting problems with assets securitized in the U.S., but it is possible that a disaggregated analysis of M3 and its counterparts may have provided some early warning signs of potential problems at euro-area banks.

\footnotetext{
${ }^{62}$ Securitization may broadly be defined as the process of converting a pool of designated financial assets into tradable securities backed by cash flows of the assets and their underlying collateral (see, European Securitization Forum (1999) and ECB Monthly Bulletin February 2008).
} 


\section{Box 1. Securitization and the Bank Lending Channel}

Securitization has likely affected the role money may play in the economy and may have increased further the distortions of the empirically small signal from money to prices. The bank lending channel asserts a direct link between central bank money and bank loan supply, which in turn affects demand, output and prices (see Section III). ${ }^{63}$ Diamond and Rajan (2006) highlight the three key assumptions usually underlying the bank lending channel: (a) binding reserve requirements that limit the issuance of bank deposits; (b) banks cannot easily replace deposit funding with other sources, such as new equity issues or other forms of short-term debt; (c) some borrowers cannot substitute bank loans with other forms of finance. The virtual elimination of reserve requirements has led many to believe that the importance of the bank lending channel has likely diminished over time. Diamond and Rajan (2006) show, however, that even without reserve requirements money may play an important role in the banking sector but assumptions (b) and (c) remain critical.

In the euro area, deposit funding, on average, remains the main funding source for banks, but other funding sources seem to become more important. From December 1998 to December 2007, the ratio of overnight deposits and short-term deposits with a maturity of less than three months to other financial bank liabilities against the private sector fell from 64 percent to 52 percent. In particular, the issuance of short-term debt securities rose sharply, albeit from a low level.

Securitization has also affected the business model of commercial banks and has likely lowered the share of bank-dependent borrowers in some countries. Banks can now securitize and sell some of their loans on to the market and rather originate and distribute loans instead of engaging in maturity transformation and credit creation. Accordingly, securitization is raising the degree of substitutability of bank loans with other forms of finance. ECB staff and others estimate that, in 2007, the annual growth rate of total loans originated by MFIs may have been 1-2 percentage points higher than the growth rate of traditional bank loans (about 11 percent in 2007) which were not sold on to the market. ${ }^{64}$

Over time, financial innovation, including securitization, is likely to further diminish the relative importance of the bank lending channel. As already emphasized by Romer and Romer (1992), it has become much easier for banks to raise funds other than deposits over the past decades. Loutskina and Strahan (2006) find that in the U.S. securitization has weakened the link from bank funding conditions to credit supply. Bernanke (2007) states that in the U.S. today the traditional bank-lending channel seems unlikely to be quantitatively important but may still be operative in economies that remain relatively more bank-dependent. However, recent research by Altunbas and others (2007) found that securitization has also significantly reduced the importance of the bank lending channel in the euro area.

\footnotetext{
${ }^{63}$ It is important to reiterate that money does not affect prices directly according the bank lending channel but through its impact on demand and output, see Bernanke and Gertler (1995).

${ }^{64}$ ECB Monthly Bulletin February 2008, p. 91 and Altunbas et al (2007). Gross euro area securitization issuance of about euro 300 billion amounts to roughly 2 percentage point but not all of this was passed on by banks via "true sales", or sold on to the market at all.
} 
For example, in late 2006/early 2007 the amount on German banks' balance sheets of securities issued by non-euro-area residents suddenly rose sharply (Figure 8). A plausible conjecture is that this surge also reflected the increasing inability of some German banks to hold these securities in off-balance sheet vehicles due to rising funding pressure. This example and its hypothesis may prove wrong at closer inspection but it illustrates the potential use of disaggregated monetary analysis for financial stability considerations.

Figure 8: Decomposition of Net-Assets of German Banks vis-à-vis Non-Residents (annual flows, billion of euros)

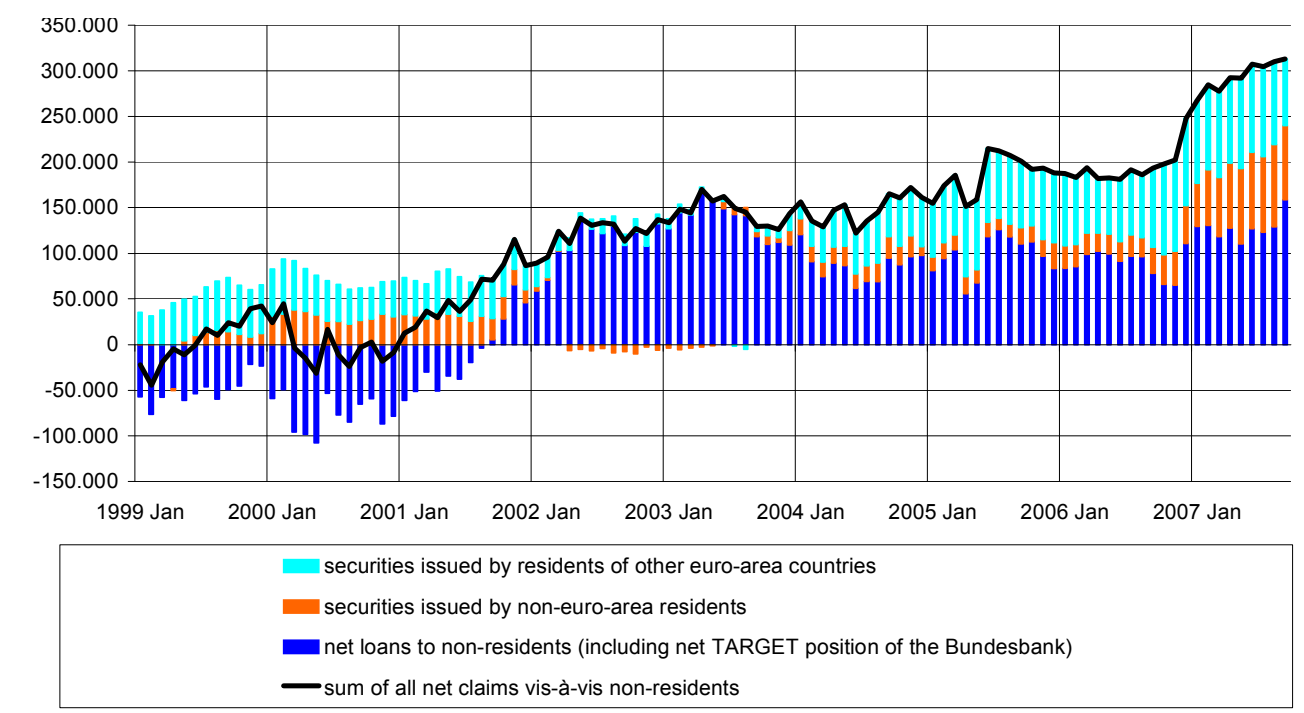

Source: Reischle (2007).

\section{Summary}

Secular changes in the economy due to financial innovation and integration seriously complicate the systematic use the ECB's M3-based reference value concept. Empirical specifications of money demand or the income velocity of money have become increasingly unstable over time and that trend, already highly visible in the U.S., is likely to continue in the euro area as well. The ECB, which seems to share this assessment, has turned to judgmental adjustments of M3 to preserve any information M3 growth might hold with regard to future price developments. These adjustments have played a crucial role in the ECB's disaggregate monetary analysis, which encompasses a detailed analysis of monetary aggregates, their components and counterparts, as recorded in the consolidated balance sheet of the euro area monetary financial institutions.

Not unlike the stability of money demand functions, however, reliable judgmental adjustment of monetary aggregates is increasingly difficult to achieve. In principle, one should expect such adjustments to be targeting obvious, unique, and relatively short lived technical or behavioral phenomena that either do not require or do not allow structural modeling. But financial innovation and integration as well as technological advance - which are among the likely forces underlying recent surges in M3 growth - are unlikely to satisfy these requirements. Moreover, their unpredictable and erratic character and their often complex 
effects on monetary aggregates make real time adjustments to these aggregates a formidable task.

A case in point is the judgmental ECB correction of portfolio shifts in the euro area during 2001-03 and the absence of further corrections afterwards. While the ECB may indeed have corrected portfolio effects on M3 in a timely and accurate fashion, these adjustments did little to alter the medium-run instability of velocity. It remains unclear, for example, to which degree more recent financial phenomena like securitization are behind the more recent surge in euro-area M3 growth and decline in velocity. In the absence of any such adjustments, however, the indicator quality of M3 growth for medium- to long-term inflation remains doubtful.

That said, in particular the ongoing debate on the role of securitization points to a separate (or possibly alternative) function of a disaggregate perspective on monetary developments. The detailed analysis of monetary components and counterparts in the consolidated balance sheet of euro area monetary banks and other financial institutions may provide useful input into the ECB's assessment of financial stability.

\section{How Time Path Dependent Should the ECB's Monetary Strategy Be?}

Economic theory suggests that a central bank's reputation is crucial to anchor private sector inflation expectations. ${ }^{65}$ In the presence of nominal rigidities, firms will set relative prices under uncertainty about the development of the general price level, which (at least in part) depends on monetary policy. If the central bank is credible in its commitment to keep inflation low, the price setting of the private sector will reflect this commitment and equilibrium inflation will be low as well. In a repeated game (and in reality price setting certainly qualifies as a repeated activity) the credibility of the central bank will critically depend on it own past actions or reputation - and here a certain institutional time-path dependency can be an advantage.

For the ECB, quickly establishing high inflation-fighting credentials may have been particularly important - and linking its monetary strategy to that of the German Bundesbank proved helpful in this regard. Speed was critical simply because the ECB was a new institution without an established track record or reputation. Further urgency was added by the fact that the ECB stepped on the stage during a time of intensive structural change caused by the transformation of euro area institutions before 1999 and the introduction of the common currency (ECB 1999, Jaeger 2003). As a result, the uncertainties about typical shocks hitting the area, their propagation, and the monetary transmission mechanism increased. As Issing (2006, p.3) emphasizes, this type of uncertainty was among the arguments behind the ECB's decision to stress the continuity of its policy framework with

${ }^{65}$ See, among others, Kydland and Prescott (1977) and Fudenberg and Maskin (1986) for important contributions to the literature on reputation and the so-called inflation bias. Walsh (2003), Clarida and others (1999), and Woodford (2003) discuss the related problem of a stabilization bias. 
"the best performers of national central banks participating in monetary union, and especially with the Bundesbank." 66

To that end, the ECB's monetary strategy announced in late 1998 included a strong reference to the German central bank's monetary targeting framework. While the ECB stopped well short of establishing announcing an intermediate money growth target (see Section II), it did little to downplay the importance of the "monetary pillar" in its communication with the public. For example, answering a question on the relative importance of the "two pillars", ECB President Duisenberg noted that "it is not a coincidence that I have used the words that money will play a prominent role. So if you call it the two pillars, one pillar is thicker than the other is, or stronger than the other, but how much I couldn't tell you." ${ }^{67}$ And Woodford (2006 p.42) concedes that the two-pillar approach served as a useful signal of the "new institution's fidelity to principles stressed earlier by the Bundesbank, which had in turn played a critical role as the anchor of the previous EMS." 68

The question is, however, whether fidelity to Bundesbank principles is still required on reputational grounds. There are no compelling arguments that support such a case. Clearly, the ECB's own reputation as an inflation-averse central bank is now well established, with long-run inflation expectations in the euro area more firmly anchored than in the United States (Beechey and others, 2008), and there is reason to suspect that the ECB's credibility does not rest predominantly on the "monetary pillar." In fact, since 1998, the ECB decreased the weight it attached to money in its monetary strategy along a number of dimensions. At an institutional level, the subtle downgrading of the importance of money in the ECB's monetary strategy after the 2003 monetary policy evaluation has markedly increased the difference between the ECB's and the Bundesbank's monetary strategy (see Section II). In addition, Berger and others (2006) provide evidence that the ECB has paid continuously less attention to the monetary analysis in its words and deeds. Based on a content-analysis of the Governing Council's introductory statements for its post-meeting press conferences, they show that the overall policy inclinations communicated by the Governing Council became increasingly less correlated with the monetary analysis contained in the statements. The same holds with regard to interest rate decisions.

As a consequence, ECB observers and financial markets have stopped to attach much weight to the ECB's monetary analysis. For example, Geraats and others (2008, p.13) point out that, despite the 2003 modification in the monetary strategy, "there remains much uncertainty

\footnotetext{
${ }^{66}$ It is interesting to note that the Bundesbank was in a similar situation at the onset of the European Monetary System (EMS) in 1979, when several of members of its Council were initially directly in favor of abandoning monetary targeting strategy. However, as von Hagen (1999) writes, later on they acknowledged the importance of "the high reputation the strategy had gained the Bank abroad" and supported the strategy, recognizing that its abandoning "the time when the new EMS was beginning to operate would create the impression that the Bundesbank was giving up on its efforts to maintain price stability and would fuel inflation expectations".

${ }^{67}$ See Issing (2006, p.2) and Jaeger (2002). A certain overplaying of the importance of monetary targeting in actual decision-making was also part of the Bundesbank's monetary strategy (see, for instance, Posen 2000).

${ }^{68}$ Interestingly, the updated version of the paper omits this passage — see Woodford (2007). Of course.
} 
regarding the role of the long-term, monetary pillar," and, in light of the noisiness of the monetary analysis, many ECB watchers and the media seem to focus more on the economic analysis. Other studies show that financial markets have ceased paying attention to Governing Council's communications regarding monetary analysis and react mostly to price news, or the economic analysis. In particular, based on the analysis of high-frequency interest rate data for horizons of up to twelve months, Lamla and Rupprecht (2006) find that the ECB's comments on price developments - which tend to be based on its economic analysis - during the press conference after Governing Council meetings are strongly reflected in financial market activity controlling for other determinants, while there is no discernible reaction whatsoever to the ECB's interpretation of developments in monetary aggregates. ${ }^{69}$ Conrad and Lamla (2007) show that, based on the high-frequency response of the euro-U.S. dollar exchange rate, ECB information on price developments are considered news by forex market participants, but that the ECB's assessments of developments in the monetary sector are not.

According to recent ECB research, a broadly similar picture emerges from the financial market reaction to the monthly release of M3 data. On the one hand, looking at intraday market reactions across the yield curve, Coffinet and Gouteron (2007) report that market rates between a horizon of one and five years react significantly to M3 growth surprises over their full sample period from November 2000 to November 2006. However, as in Lamla and Rupprecht (2006) there is no significant impact on interest rates at shorter horizons and, somewhat unexpectedly perhaps given the longer-run nature of the ECB's monetary analysis framework, at horizons beyond five years. And, even more importantly, Coffinet and Gouteron (2007) show that across all interest rate horizons the impact of M3 news has dramatically decreased over time, essentially becoming insignificant before or around the time of the ECB's monetary strategy clarification in 2003. The authors explain the fact that financial markets stopped listening to M3 announcements, in part, by a learning process, arguing that by 2003 market participants had understood that per ECB strategy changes in M3 had no immediate and mechanical impact on present policy rates. Of course, the results also imply that, in addition, markets concluded that there was little systematic information to be extracted from M3 about medium- or longer-term ECB actions and their impact on interest rates either. ${ }^{70}$

In summary, there is little reason to expect that among sophisticated investors and observers further changes in the role of monetary analysis within the ECB's wider monetary strategy will have significant impact on the ECB's reputation as a price-stability oriented central bank. Whether it might have an impact among the broader public in countries that prior to EMU also ran on a two-pillar system is a question that has not been addressed in the

\footnotetext{
${ }^{69}$ Their basic setup is a regression of the change in the Euribor rate on the post-meeting policy rate surprise (i.e., the difference between the actual post-meeting policy rate and the expected rate) and an communication indicator based on Berger and others (2006).

${ }^{70}$ In a related result, Buliř and others (2008) report that there are indications that information on the ECB's policy inclination based on the „monetary pillar" is frequently out of sync with other signals send by the ECB, including the staff's inflation forecast, press releases, or monthly bulletins.
} 
literature. But there are few reasons to believe that it would, provided the transition is well managed and takes place during a period of price stability. The bottom line is that institutional time path dependency should matter less today than in 1998 or even 2003.

\section{Conclusions}

Money plays an important role in the European Central Bank's (ECB's) monetary policy strategy. The prime function of monetary analysis today is to provide a so-called cross-check of the outcome of the economic analysis. The continued explicit reliance on money to guide monetary policy is a distinguishing feature of the ECB's framework compared to that of other central banks.

In practice, the implementation of the money-based element of the ECB's policy strategy has been challenging. In particular, the repeated surges of nominal M3 growth beyond the ECB's reference value have made it increasingly difficult for outside observers to understand the transmission of monetary analysis into policy action. The problem is that velocity is not constant and money is not fully exogenous. As a result, financial markets appear to put less and less weight on the signals from the monetary analysis, focusing mostly on the economic analysis. Providing a clear, consistent, and unified narrative about the role of money in the economy seems essential to improve on this state of affairs.

The analysis in this paper suggests that there is a strong case for presenting monetary and economic analysis using a unified framework, thereby affording monetary analysis a continued role in the ECB's overall monetary strategy. An exclusive focus on non-monetary (or "economic", in ECB parlance) factors alone may leave euro-area policy makers with an incomplete picture of the economy. However, treating monetary factors as a separate matter, using potentially inferior partial-equilibrium tools to cross-check the implications of the "economic pillar", is a second-best solution to this problem. Instead, a general-equilibrium inspired analytical framework that merges the two "pillars" of the ECB's monetary strategy appears the most promising way forward. Of course, just as the current "monetary pillar" is not explicitly linked to a particular partial equilibrium model, the merged framework will not be reduced to a specific general equilibrium model either. However, it would provide a better framework to study the interaction of money with other economic variables, including, for example, asset prices or financial sector variables, and their relations with consumer prices.

However, the evidence presented in this paper suggests that the role played by money in such unified framework may be rather limited. From a forecasting viewpoint, for example, money contains relevant information for inflation but its value-added is often small. In addition, non-monetary models generally provide better inflation forecasts than money-based models. This, of course, is not to deny that disaggregate monitoring of monetary/financial variables may be very helpful with regard to other economic or financial stability issues.

Overall, the current state of affairs could, over time, gradually detract from the credibility of the ECB and undermine potential benefits from improved monetary analysis in the future. While there is potentially much to be gained from further work on monetary analysis, it appears more productive to refine the monetary strategy in the context of a unified framework. 


\section{REFERENCES}

Alesina , Alberto, Olivier Blanchard, Jordi Galí , Francesco Giavazzi, and Harald Uhlig (2001a), Defining a Macroeconomic Framework for the Euro Area, Monitoring the European Central Bank No. 3, CEPR: London.

Alesina , Alberto, Olivier Blanchard, Jordi Galí , Francesco Giavazzi, and Harald Uhlig (2001b), MECB Update, CEPR: London.

Altunbas, Y., L. Gambacorta, and D. Marques (2007), Securitization and the Bank Lending Channel, ECB Working Paper, 838.

Andrés, Javier David López-Salido, and Javier Vallés (2006), Money in an Estimated Business Cycle Model of the Euro Area, Economic Journal, 116, April, 457-77.

Andrés, Javier, David López-Salido, and Edward Nelson (2007), Money and the Natural Rate of Interest: Structural Estimates for the UK, the US and the Euro Area, Research Division Federal Reserve Bank of St. Louis Working Paper Series, 2007-05A.

Angeloni, Ignazio, Anil Kashyap, Benoit Mojon, and Daniele Terlizzese (2002), Monetary Transmission in the Euro Area: Where Do We Stand?, ECB Working Paper, 114.

Aoki, Kosuke (2006), Optimal Commitment Policy under Noisy Information, Journal of Economic Dynamics and Control, 30(1) 81-109.

Ashley, R., Clive W. J. Granger and R. Schmalensee (1980), “Advertising and Aggregate Consumption: An Analysis of Causality", Econometrica 48, 1149-67.

Assenmacher-Wesche, Katrin and Stefan Gerlach (2006a), Interpreting Euro Area Inflation at High and Low Frequencies, BIS Working Paper, 195.

Assenmacher-Wesche, Katrin and Stefan Gerlach (2006b), Understanding the Link between Money Growth and Inflation in the Euro Area, Manuscript, February.

Assenmacher-Wesche, Katrin, Stefan Gerlach, and Toshitaka Sekine (2007), Monetary Factors and Inflation in Japan, Manuscript, January.

Backhus, David and Patrick Kehoe (1992), International Evidence of the Historical Properties of Business Cycles, American Economic Review, 82(4), 864-88.

Beck, Guenter and Volker Wieland (2007a), Money in Monetary Policy Design under Uncertainty: A Formal Characterization of ECB-Style Cross-Checking, Journal of the European Economic Association, 5(2-3), 524-33. 
Beck, Guenter and Volker Wieland (2007b), Money in Monetary Policy Design under Uncertainty: The Two-Pillar Phillips Curve versus ECB-Style Cross-Checking, Manuscript.

Beechey, Meredith J., Benjamin K. Johannsen, and Andrew T. Levin (2008), Are Long-Run Inflation Expectations Anchored More Firmly in the Euro Area than in the United States?, Finance and Economics Discussion Series, Federal Reserve Board, Washington, D.C.

Benati, Luca, (2005) Long-Run Evidence on Money Growth and Inflation, Bank of England Quarterly Bulletin, Autumn, 349-55.

Benhabib, Jess, Stephanie Schmitt-Grohe, and Martin Uribe (2001a), Monetary Policy and Multiple Equilibria, American Economic Review, 91(1), 167-86.

Benhabib, Jess, Stephanie Schmitt-Grohe, and Martin Uribe (2001b), The Perils of Taylor Rules, Journal of Economic Theory, 96(1), 40-69.

Berger, Helge and Emil Stavrev (2008), The Information Content of Money in Forecasting Euro Area Inflation, IMF Working Papers (forthcoming).

Berger, Helge and Pär Österholm (2008a), Does Money Growth Granger-Cause Inflation in the Euro Area? Evidence from Out-of-Sample Forecasts Using Bayesian VARs, IMF Working Papers, WP/08/53.

Berger, Helge and Pär Österholm (2008b), Does Money Matter for U.S. Inflation? Evidence from Bayesian VARs, IMF Working Papers, WP/08/76.

Berger, Helge and Thomas Harjes (2008), Does Global Liquidity Matter for Monetary Policy in the Euro Area?, International Monetary Fund Working Paper, forthcoming.

Berger, Helge, Jakob de Haan, and Jan-Egbert Sturm (2006), Does Money Matter in the ECB Strategy? New Evidence Based on ECB Communication, CESifo Working Paper, 1652.

Bernanke, Ben (2007), The Financial Accelerator and the Credit Channel, Speech, The Credit Channel of Monetary Policy in the Twenty-first Century Conference, Federal Reserve Bank of Atlanta, June 15, available under http:/www.federalreserve.gov/newsevents/ speech/bernanke20070615a.htm (assessed 5 March 2008).

Bernanke, Ben (2008), Monetary Aggregates and Monetary Policy at the Federal Reserve: A Historical Perspective, in: Andreas Beyer and Lucrezia Reichlin (eds.) (2008), The Role of Money-Money and Monetary Policy in the Twenty-First Century, Proceedings of the Forth ECB Central Banking Conference 9-10 November 2006, ECB: Frankfurt, 314-20.

Bernanke, Ben and Alan Blinder (1988), Credit, Money, and Aggregate Demand, American Economic Review, Papers \& Proceedings, 78, 435-39. 
Bernanke, Ben and Mark Gertler (1995), Inside the Black Box: The Credit Channel of Monetary Policy Transmission, Journal of Economic Perspectives, 9(4), 27-48.

Bernanke, Ben, Mark Gertler, and Simon Gilchrist (1996), The Financial Accelerator in a Quantitative Business Cycle Framework, Review of Economics and Statistics, 78(1), 1-15.

Bernanke, Ben, Thomas Laubach, Frederic S. Mishkin, and Adam S. Posen, (1999), Inflation Targeting: Lessons from the International Experience, Princeton: Princeton Univ. Press.

Beyer, Andreas and Lucrezia Reichlin (eds.) (2008), The Role of Money-Money and Monetary Policy in the Twenty-First Century, Proceedings of the Forth ECB Central Banking Conference 9-10 November 2006, ECB: Frankfurt.

Bini-Smaghi, Lorenzo and Daniel Gros (2000). Open Issues in European Central Banking, London: Macmillan Press.

Bloomberg (2007), Trichet, Noyer Split Over Money Supply Clouds ECB Rate Outlook, Online News Report, 4 June, available online under http://www.bloomberg.com/apps/news?pid=20601109\&sid=a.JaL_23jXV0\&refer=home\# (assessed on 13 March 2008).

Boone, Laurence, Fanny Mikol, and Paul van den Noord (2004), Wealth Effects on Money Demand in EMU: Econometric Evidence, OECD Economics Department Working Paper, 411.

Bordes, Christian and Laurent Clerc (2007), Price Stability and the ECB's Monetary Policy Strategy, Journal of Economic Surveys, 21(2), 268-325.

Bordes, Christian, Laurent Clerc, and Vêlayoudom Marimoutou (2007), Is There a Structural Break in Equilibrium Velocity in the Euro Area, Notes D'Études Et De Recherche, NERE165.

Brand, Claus, Hans-Eggert Reimers, and Franz Seitz (2003), Forecasting Real GDP: What Role for Narrow Money?, in: Issing, Otmar (ed.), Background Studies for the ECB's Evaluation of its Monetary Policy Strategy, European Central Bank: Frankfurt, 302-33.

Bruggeman, Annick, Paola Donato, and Anreas Warne (2003), Is the Demand for Euro Area M3 Stable? in: Issing, Otmar (ed.), Background Studies for the ECB's Evaluation of its Monetary Policy Strategy, European Central Bank: Frankfurt, 246-300.

Bulíŕ, Aleš, Martin Čihák, and Kateřina Šmídková (2008), Writing Clearly: ECB’s Monetary Policy Communication, IMF Working Paper (forthcoming).

Bundesbank, Deutsche (2005), The Relationship Between Money and Prices, Monthly Report, January, 13-24. 
Bundesbank, Deutsche (2007), The Relationship Between Monetary Developments and the Real Estate Market, Monthly Report, July, 13-24.

Calza, Allessandro and Joao Sousa (2003), Why Has Broad Money Demand Been More Stable in the Euro Area than in Other Economies? A Literature Review, in: Issing, Otmar (ed.), Background Studies for the ECB's Evaluation of its Monetary Policy Strategy, European Central Bank: Frankfurt, 229-43.

Calza, Allessandro, Dieter Gerdesmeier, and Joaquim Levy (2001), Euro Area Money Demand: Measuring the Opportunity Cost Appropriately, IMF Working Paper, 179/01.

Carlstrom, Charles and Timothy Fuerst (2002), Taylor Rules In A Model that Satisfies The Natural-Rate Hypothesis, American Economic Review, 92(2), 79-84.

Christiano, Lawrence and Massimo Rostagno (2001), Money Growth Monitoring and the Taylor Rule, NBER Working Paper, 8539.

Christiano, Lawrence and Terry Fitzgerald (2003), Inflation and Monetary Policy in the $20^{\text {th }}$ Century, Economic Perspectives (Federal Reserve Bank of Chicago) 1Q, 21-45.

Christiano, Lawrence, Martin Eichenbaum, and Charles Evans (1998), Monetary Policy Shocks: What Have We Learned and to What End? In: John Taylor and Michael Woodford (eds.), Handbook of Macroeconomics, Amsterdam: Elsevier, Volume 1, 65-148.

Christiano, Lawrence, Martin Eichenbaum, and Charles Evans (2005), Nominal Rigidities and the Dynamic Effects of a Shock to Monetary Policy, Journal of Political Economy, 113(1), 1-45.

Christiano, Lawrence, Roberto Motto, and Massimo Rostagno (2008), Two Reasons Why Money And Credit May Be Useful In Monetary policy, in: Andreas Beyer and Lucrezia Reichlin (eds.), The Role of Money-Money and Monetary Policy in the Twenty-First Century, Proceedings of the Forth ECB Central Banking Conference 9-10 November 2006, ECB: Frankfurt, 28-55.

Clarida, Richard , Jordi Galí, and Mark Gertler (1999). The Science of Monetary Policy: A New Keynesian Perspective, Journal of Economic Literature, 37(4), 1661-1707.

Coenen, Günter, Andrew Levin, and Volker Wieland (2005), Data Uncertainty and the Role of Money as an Informational Variable for Monetary Policy, European Economic Review, 49(4), 975-1006.

Coffinet, Jerome and Sylvain Gouteron (2007), Euro area Market Reactions to the Monetary Developments Press Release, ECB Working Paper, 792. 
Conrad, Christian and Michael Lamla (2007), The High-frequency Response of the EU-US Dollar Exchange Rate to ECB Monetary Policy Announcements, KOF Swiss Economic Institute ETH Zurich Working Paper, 07-174.

Cukierman, Alex (2001), Accountability, Credibility, Transparency, and Stabilization in the Eurosystem, in: Charles Wyplosz (ed.), The Impact of EMU on Europe and the Developing Countries, Oxford: Oxford University Press, 40-75.

D’Agostino, Antonello, Domenico Giannone, and Paolo Surico (2006), (Un)Predictability and Macroeconomic Stability, ECB Working Paper, 605.

De Grauwe, Paul and Magdalena Polan (2005), Is Inflation Always and Everywhere a Monetary Phenomenon? Scandinavian Journal of Economics, 107(2), 239-59.

Diamond, Douglas and Raghuram Rajan (2001), Liquidity Risk, Liquidity Creation, and Financial Fragility: A Theory of Banking, Journal of Political Economy, 109(2), 287-327.

Diamond, Douglas and Raghuram Rajan (2006), Money in a Theory of Banking, American Economic Review, 96(1), 30-53.

Dotsey, Michael and Andreas Hornstein (2003), Should Monetary Policy Makers Look at Money? Journal of Monetary Economics, 50(3), 547-79.

Dow Jones (2007), Weber warnt vor Aufgabe der monetären Säule in EZB-Strategie, Online News Report, 29 May, available online under http://www.djnewswires.de/news.php?id=11134 (assessed on 13 March 2008).

Dreger, Christian and Jürgen Wolters (2006), Investigating M3 Money Demand in the Euro Area - New Evidence Based on Standard Models, DIW Berlin Discussion Papers, 561.

ECB (1998), A Stability-Oriented Monetary Policy Strategy for the ESCB. Press Release, 13 October, available online under http://www.ecb.int/press/pr/date/1998/html/pr981013_1.en.html (assessed 13 March 2008).

ECB (1999), The Stability-Oriented Monetary Policy Strategy of the Eurosystem, Monthly Bulletin, January, 39-50.

ECB (2001), The Monetary Policy of the ECB, ECB: Frankfurt.

ECB (2003a), The Outcome Of The ECB's Evaluation Of Its Monetary Policy Strategy, Monthly Bulletin, June, 79-90.

ECB (2003b), The ECB's Monetary Policy Strategy. Press Release, 8 May, available online under http://www.ecb.int/press/pr/date/2003/html/pr030508_2.en.html\# (assessed 14 March 2008). 
ECB (2004a), The Monetary Policy of the ECB, Second Edition, ECB: Frankfurt.

ECB (2004b), Monetary Analysis in Real Time, Monthly Bulletin, February, 43-66.

ECB (2008), Securitisation in the Euro Area, Monthly Bulletin, February, 81-94.

ECB, Monthly Bulletin, various issues.

Ehrmann, Michael, Leonardo Gambacorta, Jorge Martinez-Pages, Patrick Sevestre, and Andreas Worms (2003), Financial Systems and the Role of Banks in Monetary Policy Transmission in the Euro Area, in: Ignazio Angeloni, Anil Kashyap, and Benoit Mojon (eds.), Monetary Policy Transmission in the Euro Area: A Study by the Eurosystem Monetary Transmission Network, Cambridge: Cambridge University Press, 235-69.

Ericsson, Neil (1998), Empirical Modeling of Money Demand, Empirical Economics 23(3), 295-315.

European Securitization Forum (1999), "European Securitization: A Resource Guide", available online under http://www.europeansecuritisation.com/esfPubs.shtml.

Faruqee, Hamid (2005), Declining Money Velocity in the Euro Area: Implications for the ECB's Monetary Analysis, IMF Country Report, 05/266, 32-61.

Fatás, Antonio, Ilian Mihov, and Andrew Rose, (2007), Quantitative Goals for Monetary Policy, Journal of Money, Credit and Banking, 39(5), 1163-76.

Ferrero, Giuseppe, Andrea Nobili, and Patrizia Passiglia (2007), The Sector Distribution of Money Supply in the Euro Area, Banca D'Italia, Temi Di Discussione Del Servizio Studi, 627.

Fischer, Björn, Michele Lenza, Huw Pill, and Lucrezia Reichlin (2008) Money and Monetary Policy: The ECB Experience 1999-2006, in: Andreas Beyer and Lucrezia Reichlin (eds.), The Role of Money-Money and Monetary Policy in the Twenty-First Century, Proceedings of the Forth ECB Central Banking Conference 9-10 November 2006, ECB: Frankfurt, 102-75.

Forni, Mario, Marc Hallin, Marco Lippi, and Lucrezia Reichlin (2003), Do Financial Variables Help Forecasting Inflation and Real Activity in the Euro Area? Journal of Monetary Economics, 50, 1243-55.

Friedman, B., and K. Kuttner (1996), A Price Target for U.S. Monetary Policy? Lessons from the Experience with Money Growth Targets, Brookings Papers on Economic Activity, 1:1996, 77-146. 
Fudenberg, Drew and Eric Maskin (1986), Folk Theorems for Repeated Games with Discounting or Incomplete Information, Econometrica, 54(3), 533-54.

Fuhrer, Jeffrey (2000), Habit Formation in Consumption and Its Implications for Monetary-Policy Models, American Economic Review, 90(3), 367-90.

Galí, Jordi (2008), Comment, in: Andreas Beyer and Lucrezia Reichlin (eds.), The Role of Money-Money and Monetary Policy in the Twenty-First Century, Proceedings of the Forth ECB Central Banking Conference 9-10 November 2006, ECB: Frankfurt, 182-89.

Galí, Jordi and Marek Gertler (2007), Macroeconomic Modeling for Monetary Policy Evaluation, Universitat Pompeu Fabra Department of Economics and Business Working Papers, 1039.

Galí, Jordi, Stefan Gerlach, Julio Rotemberg, Harald Uhlig, and Michael Woodford (2004), The Monetary Policy Strategy of the ECB Reconsidered, Monitoring the European Central Bank No. 5, CEPR: London.

Geraats, Petra, Francesco Giavazzi, and Charles Wyplosz (2008), Transparency and Governance, Monitoring the European Central Bank No. 6, CEPR: London.

Gerlach, Stefan (2004), The Two Pillars of the European Central Bank, Economic Policy, 40, October, 389-439.

Gerlach, Stefan and Lars Svensson (2003), Money and Inflation in the Euro Area: A Case for Monetary Indicators? Journal of Monetary Economics, 50(8), 1649-72.

Golinelli, Roberto and Sergio Pastorello (2002), Modeling the Demand for M3 in the Euro Area, European Journal of Finance, 8(4), 371-401.

Goodfriend, Marvin (2000), Overcoming the Zero Bound on Interest Rate Policy, Journal of Money, Credit and Banking, 32(4), 1007-35.

Goodfriend, Marvin and Bennett McCallum (2007), Banking and Interest Rates in Monetary Policy Analysis: A Quantitative Exploration, Journal of Monetary Economics, 54(5), 1480-1507.

Greiber, Claus and Ralph Setzer (2007), Money and Housing - Evidence for the Euro Area and the US, Deutsche Bundesbank Working Paper, 12/2007.

Greiber, Claus and Wolfgang Lemke (2005), Money Demand and Macroeconomic Uncertainty, Deutsche Bundesbank Discussion Paper, 26/2005.

Haan, Jakob de, Sylvester Eijffinger, and Sandra Waller (2005). The European Central Bank. Credibility, Transparency, and Centralization, Cambridge, MA: The MIT Press. 
Hale, Galina, and Òscar Jordà (2007), Do Monetary Aggregates Help Forecast Inflation?, FRBSF Economic Letter, 2007-10, 1-3.

Hallman, Jeffrey, Richard Porter, and David Small (1991), Is the Price Level Tied to the M2 Monetary Aggregate in the Long Run? The American Economic Review, 81(4), 841-58.

Hofmann, Boris (2008), Do Monetary Indicators Lead Euro Area Inflation? ECB Working Paper, 867.

Ireland, Peter (2001), The Real Balance Effect, NBER Working Paper, 8136.

Ireland, Peter (2004), Money's Role in the Monetary Business Cycle, Journal of Money Credit and Banking, 36(6), 969-83.

Issing, Otmar (1999), The Monetary Policy of the Eurosystem, Finance \& Development, 36, $18-21$.

Issing, Otmar (2001), The Euro Area and the Single Monetary Policy, Österreichische Nationalbank Working Paper, 44.

Issing, Otmar (2006), The ECB's Monetary Policy Strategy: Why Did We Choose a Two Pillar Approach?, Speech, available online under www.ecb.int/events/pdf/conferences/cbc4/Issing.pdf (assessed 25 April 2008).

Issing, Otmar, in cooperation with Ignazio Angeloni, Vítor Gaspar, Hans-Joachim Klöckers, Klaus Masuch, Sergio Nicoletti-Altimari, Massimo Rostagno, and Frank Smets (eds.) (2003), Background Studies for the ECB's Evaluation of its Monetary Policy Strategy, ECB: Frankfurt.

Issing, Otmar, Vitor Gaspar, Ignazio Angeloni, and Oreste Tristani (2001), Monetary Policy in the Euro Area: Strategy and Decision Making at the European Central Bank, Cambridge: Cambridge University Press.

Jaeger, Albert (2003), The ECB's Money Pillar: An Assessment, IMF Working Papers, $\mathrm{WP} / 03 / 82$.

Jones, Barry and Livio Stracca (2006), Are Money and Consumption Additively Separable in the Euro Area? A Non-Parametric Approach, ECB Working Paper, 704.

Kahn, George and Scott Benolkin (2007), The Role of Money in Monetary Policy: Why do the Fed and the ECB See It So Differently?, Federal Reserve Bank of Kansas City Economic Review, Third Quarter, 5-36.

Kremer, Jana, Giovanni Lombardo, and Thomas Werner (2003), Money in a New-Keynesian Model Estimated with German Data, Deutsche Bundesbank Discussion Paper, 15/2003. 
Kydland, Finn and Edward Prescott (1977) Rules Rather Than Discretion: The Inconsistency of Optimal Plans, Journal of Political Economy, 85(3), 473-91.

Lamla, Michael and Sarah Rupprecht (2006), The Impact of ECB Communication on Financial Market Expectations, KOF Swiss Economic Institute, ETH Zurich Working Paper, 06-135.

Leeper, Eric and Jennifer Roush (2003), Putting "M" Back in Monetary Policy, Journal of Money, Credit and Banking, 35(6), 1217-57.

Leeper, Eric, Christoper Sims, and Tao Zah (1996), What Does Monetary Policy Do? Brookings Papers on Economic Activity, 2, 1-78.

Loutskina, Elena and Philip Strahan (2008), Securitization and the Declining Impact of Bank Finance on Loan Supply: Evidence from Mortgage Originators, Manuscript, January.

Lubik, Thomas and Paolo Surico (2006), The Lucas Critique and the Stability of Empirical Models, Federal Reserve Bank of Richmond Working Paper, 06-05.

Lucas, Robert (1980), Two Illustrations of the Quantity Theory of Money, American Economic Review, 70(5), 1005-14.

Lucas, Robert (1986), Adaptive Behavior and Economic Theory, The Journal of Business, 59(4), 401-26.

Masuch, Klaus, Huw Pill, and Caroline Willeke (2001), Framework and Tools of Monetary Analysis, in: Hans-Joachim Klöckers and Caroline Willeke, Monetary Analysis: Tools and Applications, European Central Bank: Frankfurt, 117-44.

Masuch, Klaus, Nicoletti, Sergio Altimari, Massimo Rostagno, and Huw Pill (2003), The Role of Money in Monetary Policymaking, in: Issing, Otmar (ed.), Background Studies for the ECB's Evaluation of its Monetary Policy Strategy, European Central Bank: Frankfurt, 187-228.

McCallum, Bennett (1981), Price Level Determinacy with an Interest Rate Rule and Rational Expectations, Journal of Monetary Economics, 8(3), 319-29.

McCallum, Bennett (2001), Monetary Policy Analysis in Models without Money, NBER Working Paper, 8174.

McCallum, Bennett (2003), Multiple-Solution Indeterminacies In Monetary Policy Analysis, Journal of Monetary Economics, 50(5), 1153-75.

Meltzer, Allan (2001), The Transmission Process, in: Deutsche Bundesbank (ed.), The Monetary Transmission Process: Recent Developments and Lessons For Europe, Palgrave: London, 112-30. 
Nelson, Edward (2002), Direct Effects of Base Money on Aggregate Demand: Theory and Evidence, Journal of Monetary Economics, 49(4), 687-708.

Nelson, Edward (2003), The Future of Monetary Aggregates in Monetary Policy Analysis, Journal of Monetary Economics, 50(5), 1029-59.

Nelson, Edward (2007), Comment on: Samuel Reynard, “Maintaining Low Inflation”, Journal of Monetary Economics, 54(5), 1472-79.

Neumann, Manfred (1997), Monetary Targeting in Germany, in: Iwao Kuroda (ed.), Towards More Effective Monetary Policy, London: Macmillan, 176-210.

Neumann, Manfred (2003), The European Central Bank’s First Pillar Reassessed, Manuscript.

Neumann, Manfred and Claus Greiber (2004), Inflation and Core Money Growth in the Euro Area, Deutsche Bundesbank Discussion Paper, 36/2004.

Nicoletti-Altimari, Sergio (2001) Does Money Lead Inflation in the Euro Area?, ECB Working Paper, 63.

Noyer, Christan (2007), Financial Innovation, Monetary Policy, and Financial Stability, Speech, 17 April, available online under http://www.banquefrance.fr/gb/instit/telechar/discours/20070428.pdf (assessed 13 March 2008).

OECD (2007), Economic Survey of the Euro Area 2007: The Role of Monetary Aggregates in Monetary Policy, OECD: Paris.

Orphanides, Athanasios (2003), Historical Monetary Policy Analysis and the Taylor Rule, Journal of Monetary Economics, 50(5), 983-1022.

Orphanides, Athanasios and Richard Porter (2000), P* Revisited: Money-Based Inflation Forecasts with a Changing Equilibrium Velocity, Journal of Economics and Business, $52(1 / 2), 87-100$.

Papademos, Lucas (2006), The Role of Money in the Conduct of Monetary Policy, speech given at the Fourth ECB Central Banking Conference "The Role of Money: Money and Monetary Policy in the Twenty-first Century”, Frankfurt am Main, November, 2006. Online access at: http://www.ecb.int/press/key/date/2006/html/sp061110.en.html

Pill, Huw and Tuomas Rautanen (2006), Monetary Analysis: The ECB Experience, Manuscript, Frankfurt.

Posen Adam. (2000), Lessons from the Bundesbank on the Occasion of its Early Retirement, in: Lavan Mahadeva and Gabriel Sterne (eds.), Monetary Policy Frameworks in a Global Context, London: Routledge, 393-421. 
Reischle, Julian (2007), Recent Developments in the Net External Asset Aosition of German Banks, Manuscript (presented at ECB Workshop "The External Dimension of Monetary Analysis“ in Frankfurt/Germany, December).

Reuters (2007), Papademos tritt Zweifeln an EZB-Strategie entgegen, Online News Report, 12 June, assessed online on 13 August 2007 under http://de.today.reuters.com/news/newsArticle.aspx?type=economicsNews\&storyID=2007 -06-12T173253Z 01_HUM263163_RTRDEOC 0 EZB-STRATEGIEPAPADEMOS.xml.

Reynard, Samuel (2007), Maintaining Low Inflation, Money, Interest Rates, and Policy Stance, Journal of Monetary Economics, 54(5), 1441-71.

Roffia, Barbara and Andrea Zaghini (2007), Excess Money Growth and Inflation Dynamics, ECB Working Paper, 749.

Romer, C., and D. Romer (1992), "New Evidence on the Monetary Transmision Mechanism" Brookings Papers on Economic Activity, pp. 149-98.

Rudebusch, Glenn and Lars Svensson (2002), Eurosystem Monetary Targeting: Lessons From U.S. Data, European Economic Review, 46(3), 417-42.

Sargent, Thomas. and Neil Wallace (1975), Rational" Expectations, the Optimal Monetary Instrument, and the Optimal Money Supply Rule, Journal of Political Economy, 83(2), 241-54.

Scharnagl, Michael and Christian Schumacher (2007), Reconsidering the Role of Monetary Indicators for Euro Area Inflation from a Bayesian Perspective Using Group Inclusion Probabilities, Deutsche Bundesbank Discussion Paper, 09/2007.

Smets, Frank (2003), Discussion "Putting "M" Back in Monetary Policy", Journal of Money, Credit and Banking, 35(6), 1257-64.

Stavrev, Emil (2006), Measures of Underlying Inflation in the Euro Area: Assessment and Role for Informing Monetary Policy, IMF Working Paper, WP/06/197.

Svensson, Lars (2000), Does the P* Model Provide Any Rationale for Monetary Targeting? German Economic Review, 1, 69-81.

Svensson, Lars (2003), Comment on: "Nelson (2003), The Future of Monetary Aggregates in Monetary Policy",Journal of Monetary Economics, 50, 1061-70.

Tödter, Karl-Heinz and Hans-Eggert Reimers (1997), P-star As a Link Between Money and Prices in Germany, Weltwirtschaftliches Archiv, 130, 273-89. 
Uhlig, Harald (2008), Comment, in: Andreas Beyer and Lucrezia Reichlin (eds.), The Role of Money-Money and Monetary Policy in the Twenty-First Century, Proceedings of the Forth ECB Central Banking Conference 9-10 November 2006, ECB: Frankfurt, 87-96.

Van den Heuvel, Skander (2007), The Bank Capital Channel of Monetary Policy, Manuscript, University of Pennsylvania.

von Hagen, Jürgen (1999), Money Growth Targeting by the Bundesbank, Journal of Monetary Economics, 43, 681-701.

von Hagen, Jürgen (2003), Hat die Geldmenge ausgedient? Perspektiven der Wirtschaftspolitik, 5(4), 423-53.

Woodford, Michael (2003), Interest and Prices: Foundations of a Theory of Monetary Policy, Princeton University Press: Princeton.

Woodford, Michael (2006), How Important is Money in the Conduct of Monetary Policy, Queen's Economics Department Working Paper, 1104.

Woodford, Michael (2007), How Important is Money in the Conduct of Monetary Policy, NBER Working Paper, 13325.

Woodford, Michael (2008), Does a "Two-Pillar Phillips Curve" Justify a Two-Pillar Monetary Policy Strategy? in: Andreas Beyer and Lucrezia Reichlin (eds.), The Role of Money-Money and Monetary Policy in the Twenty-First Century, Proceedings of the Forth ECB Central Banking Conference 9-10 November 2006, ECB: Frankfurt, 56-82. 


\section{Diskussionsbeiträge des Fachbereichs Wirtschaftswissenschaft der Freien Universität Berlin}

2008

$2008 / 1$

EICHFELDER, Sebastian

Die Gründung der Bankgesellschaft Berlin : 1988 - 1996

Betriebswirtschaftliche Reihe

$2008 / 2$

WIENEN, Julia / Christina SICHTMANN

Vom Produkt zur Solution bei Industriegütern : Literaturüberblick und praktische

Ansatzpunkte

Betriebswirtschaftliche Reihe

$2008 / 3$

SCHULARICK, Moritz / Thomas M. STEGER

The Lucas Paradox and the Quality of Institutions: Then and Now

Volkswirtschaftliche Reihe

2008/4 BÖNKE, Timm / Carsten SCHRÖDER / Katharina SCHULTE

Incomes and inequality in the long run : the case of German elderly

Volkswirtschaftliche Reihe

2008/5 BERGER, Helge / Volker NITSCH / Tonny LYBEK

Central Bank Boards around the World: Why does Membership Size Differ?

Volkswirtschaftliche Reihe

2008/6 BERGER, Helge / Volker NITSCH

Gotcha! A Profile of Smuggling in International Trade

Volkswirtschaftliche Reihe

2008/7 BERGER, Helge / Pär ÖSTERHOLM

Does Money Still Matter for U. S. Output?

Volkswirtschaftliche Reihe

2008/8 BERGER, Helge / Volker NITSCH

Too Many Cooks? Committees in Monetary Policy

Volkswirtschaftliche Reihe

2008/9 BERGER, Helge / Pär ÖSTERHOLM

Does Money Matter for U. S. Inflation? Evidence from Bayesian VARs

Volkswirtschaftliche Reihe

2008/10 BERGER, Helge / Pär ÖSTERHOLM

Does Money Growth Granger-Cause Inflation in the Euro Area? Evidence from Out-

of-Sample Forecasts Using Bayesian VARs

Volkswirtschaftliche Reihe

2008/11 BERGER, Helge / Michael EHRMANN / Marcel FRATZSCHER

Geography or Skills? What Explains Fed Wachters' Forecast Accuracy of US

Monetary Policy?

Volkswirtschaftliche Reihe

2008/12 BERGER, Helge / Anika HOLLER

What determines Fiscal Policy? Evidence from German States

Volkswirtschaftliche Reihe 
2008/14 BERGER, Helge / Thomas HARJES / Emil STAVREV

The ECB's Monetary Analysis Revisited

Volkswirtschaftliche Reihe

2008/15 BERGER, Helge / Emil STAVREV

The Information Content of Money in Forecasting Euro Area Inflation Volkswirtschaftliche Reihe 